\title{
Combining chirality and hydrogen bonding in methylated ethylenedithio- tetrathiafulvalene primary diamide precursors and radical cation salts
}

Nabil Mroweh, ${ }^{\dagger}$ Flavia Pop, ${ }^{*}{ }^{\dagger}$ Cécile Mézière, ${ }^{\dagger}$ Magali Allain, ${ }^{\dagger}$ Pascale Auban-Senzier, ${ }^{\ddagger}$ Nicolas Vanthuyne, $"$ Pere Alemany, ${ }^{\diamond}$ Enric Canadell,, and Narcis Avarvari*, ${ }^{\dagger}$

${ }^{\dagger}$ MOLTECH-Anjou, UMR 6200, CNRS, UNIV Angers, 2 bd Lavoisier, 49045 ANGERS Cedex, France. Tel: 33.(0)2.41.73.50.84;

Fax: 33.(0)2.41.73.54.05. E-mail: flavia.pop@univ-angers.fr; narcis.avarvari@univ-angers.fr

‡Université Paris-Saclay, CNRS, Laboratoire de Physiques des Solides, 91405, Orsay, France

"Aix Marseille Université, CNRS, Centrale Marseille, iSm2, Marseille, France

${ }^{\diamond}$ Departament de Ciència de Materials i Química Física and Institut de Química Teòrica i Computacional (IQTCUB), Universitat de Barcelona, Martí i Franques 1, Barcelona 08028, Spain

\# Institut de Ciència de Materials de Barcelona (CSIC), Campus de la UAB, E-08193 Bellaterra, Spain

\section{ABSTRACT:}

Methyl- and dimethyl-ethylenedithio-tetrathiafulvalene ortho-diamide donors Me-EDT-TTF $\left(\mathrm{CONH}_{2}\right)_{2}(\mathbf{1 a})$ and DM-EDT-TTF $\left(\mathrm{CONH}_{2}\right)_{2}$ (1) have been prepared by the direct reaction of the corresponding diester precursors with aqueous ammonia solutions. The neutral ( $r a c)-\mathbf{1 a},(S)-\mathbf{1 a}$ and $(S, S)-\mathbf{1} \mathbf{b}$ donors have been characterized by single crystal X-ray diffraction. In the three compounds, which crystallized in the non-centrosymmetric monoclinic space-group $P 2_{1}$, the amide groups are disordered, yet they form the classical intramolecular hydrogen bond for such ortho-diamide motif. Electrocrystallization experiments afforded the mixed valence radical cation salts $[(S, S)-\mathbf{1 b}]_{2} \mathrm{XO}_{4}$ and $[(R, R)-\mathbf{1} \mathbf{b}]_{2} \mathrm{XO}_{4}(\mathrm{X}=\mathrm{Cl}, \mathrm{Re})$ containing four independent donors in the asymmetric unit, with the positive charge localized essentially on two donors while the two others are neutral. The topology of the organic layer is of $\beta^{\prime}$-type. Single crystal resistivity measurements show semiconducting behavior for $[(S, S)-\mathbf{1 b}]_{2} \mathrm{ClO}_{4}$ and $[(R, R)-\mathbf{1 b}]_{2} \mathrm{ReO}_{4}$, with a room temperature conductivity of $510^{-5} \mathrm{~S} \mathrm{~cm}^{-1}$ and activation energies $E_{a} \approx 3000 \mathrm{~K}$. Tight-binding band structure calculations of extended Hückel type in combination with DFT calculations are in agreement with the semiconducting behavior and suggest a localized Mott type semiconductor rather than a band gap semiconductor.

\section{INTRODUCTION}

Functionalization of tetrathiafulvalenes (TTF), a well-known electroactive platform for donor-acceptor systems, ${ }^{1,2,3}$ molecular conductors and superconductors, ${ }^{4,5}$ switchable systems, ${ }^{6}$ and redox-active ligands and complexes, ${ }^{7}$ with hydrogen bonding units provides an access to electroactive precursors and materials in which intra- and intermolecular hydrogen bonds play an important role in the resulting solid state architectures as they compete with other intermolecular interactions such as $\pi-\pi$ stacking, S $\cdots$ S van der Waals and orbital overlap between open shell species in the case of radical cation salts. ${ }^{8}$ Therefore various hydrogen bonding donor and/or acceptor groups such as carboxylic acids, ${ }^{9,10,11,12}$ alcohols, ${ }^{13,14,15,16,17}$ nucleobases, $^{18,19}$ imidazoles, $^{20,21,22}$ 
phenols, ${ }^{23}$ catechols ${ }^{24,25,26,27}$ have been attached to TTF either directly or through spacers. In this respect the amide function proved to be particularly prolific when considering the large number of TTF monoamides, ${ }^{28,29,30,31,32}$ ortho-diamides, ${ }^{33,34,35}$ bis(amides) ${ }^{36}$ precursors and conducting radical cation salts reported to date, including chiral derivatives such as TTF-hydroxyamides, ${ }^{37}$ TTF-tetrakis(methyl-benzamides) providing conducting helical fibers, ${ }^{38}$ binaphthyl-TTF-diamides, ${ }^{39}$ or $C_{3}$ symmetric benzene-1,3,5-tricarboxamides tris(TTF) derivatives which self-assemble in helical aggregates. ${ }^{40,41,42}$ In this respect, introduction of chirality into electroactive precursors proved its interest in recent years through the preparation of crystalline chiral conductors, $^{43,44,45}$ in which differences of conductivity have been observed between the racemic and enantiopure forms either because of structural disorder ${ }^{46,47}$ or different crystal packings. ${ }^{48,49}$ Moreover, the direct synergy between electrical conductivity and chirality through the electrical magnetochiral anisotropy effect $(\mathrm{eMChA})^{50,51}$ has been observed for the first time in crystalline chiral molecular conductors based on the dimethyl-ethylenedithio-tetrathiafulvalene (DM-EDT-TTF) donor (see in Scheme 1 the $(S, S)$ enantiomer). ${ }^{52}$ More recently, we have shown that the decrease of the number of stereogenic centers from two in DM-EDT-TTF to one in methyl-ethylenedithio-tetrathiafulvalene (Me-EDT-TTF) (see in Scheme 1 the $(R)$ enantiomer) resulted in the stabilization of a metallic triclinic phase for the enantiopure salts with the $\mathrm{PF}_{6}{ }^{-}$anion, ${ }^{53}$ compared to the semiconducting monoclinic chiral phases of DM-EDT-TTF with the same anion. ${ }^{48}$ In the work described herein we have decided to investigate the influence of the number of stereogenic centers on the ethylene bridge (one or two methyl groups), on the solid state architectures of the resulting Me-EDT-TTF(CONH $)_{2}$ and DM-EDT$\operatorname{TTF}\left(\mathrm{CONH}_{2}\right)_{2}$ donors $\mathbf{1 a}$ and $\mathbf{1} \mathbf{b}$ (Scheme 1), respectively, and the radical cation salts of the latter with the $\mathrm{ClO}_{4}{ }^{-}$ and $\mathrm{ReO}_{4}{ }^{-}$anions. The electron transport properties of the enantiopure salts of $\mathbf{1} \mathbf{b}$ have been determined and correlated with band structure calculations.

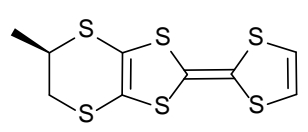

(R)-Me-EDT-TTF<smiles>C[C@H]1SC2=C(SC(=C3SC=CS3)S2)S[C@@H]1C</smiles>

(S,S)-DM-EDT-TTF<smiles>C[C@H]1CSC2=C(SC(=C3SC(C(N)=O)=C(C(N)=O)S3)S2)S1</smiles>

Me-EDT-TTF $\left(\mathrm{CONH}_{2}\right)_{2}$ (R)-1a, (S)-1a, (rac)-1a<smiles>C[C@H]1SC2=C(SC(=C3SC(C(N)=O)=C(C(N)=O)S3)S2)S[C@@H]1C</smiles>

DM-EDT-TTF $\left(\mathrm{CONH}_{2}\right)_{2}$ $(R, R)-\mathbf{1 b},(S, S)-\mathbf{1 b}$

Scheme 1. Chiral methylated EDT-TTF donors; the ortho-diamides $1 \mathrm{a}$ and $1 \mathrm{~b}$ are described in this work

\section{RESULTS AND DISCUSSION}

\section{Synthesis and characterization of the neutral donors}

The bis-amide derivatives Me-EDT-TTF $\left(\mathrm{CONH}_{2}\right)_{2}$ and DM-EDT-TTF $\left(\mathrm{CONH}_{2}\right)_{2}$ of type $\mathbf{1 a}$ and $\mathbf{1 b}$ respectively, have been obtained by amidation reactions of the previously described donors $(S)-\mathbf{2} \mathbf{a},(R)-\mathbf{2} \mathbf{a}$, racemic-2a, ${ }^{53}$ and $(S, S)$ - 
$\mathbf{2} \mathbf{b}$ and $(R, R)-\mathbf{2} \mathbf{b},{ }^{48}$ following the method described by Baudron et al. to obtain EDT-TTF $\left(\mathrm{CONH}_{2}\right)_{2}$ from the diester precursor EDT-TTF $\left(\mathrm{CO}_{2} \mathrm{Me}\right)_{2}$ (Scheme 2$) .^{33}$

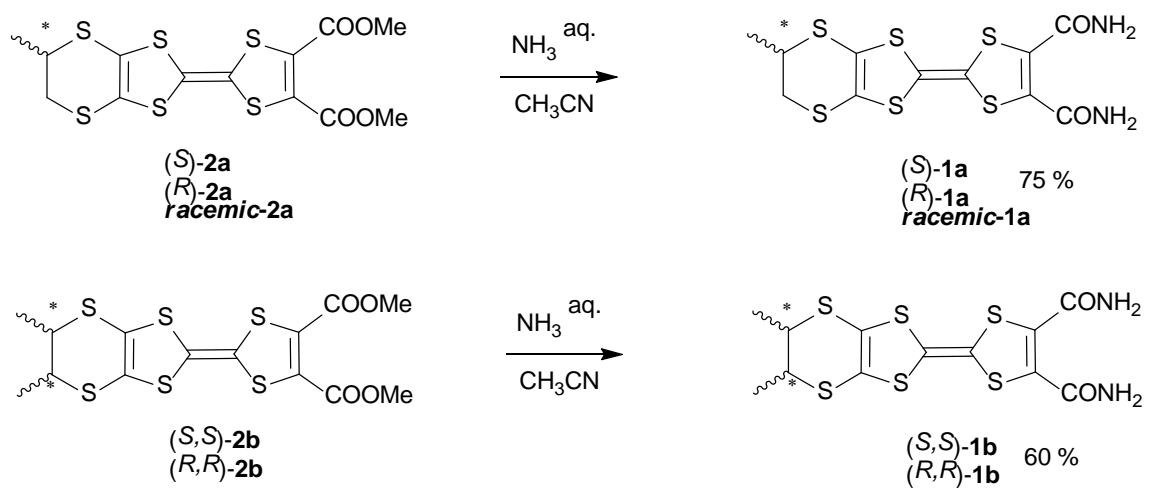

Scheme 2. Synthesis of the ortho-diamides $1 \mathrm{a}$ and $1 \mathrm{~b}$

While the diester precursor DM-EDT-TTF $\left(\mathrm{CO}_{2} \mathrm{Me}\right)_{2} \mathbf{2} \mathbf{b}$ was obtained and subsequently used as pure enantiomers, ${ }^{48} \mathrm{Me}-\mathrm{EDT}-\mathrm{TTF}\left(\mathrm{CO}_{2} \mathrm{Me}\right)_{2} 2 \mathrm{2a}$ was synthesized as racemic mixture ${ }^{53}$ which provided the pure enantiomers by chiral HPLC (see the SI). The assignment of the absolute configurations of $(S)-2 a$ and $(R)$-2a has been done by comparison of the circular dichroism (CD) spectra and the optical rotations (see the SI) with those of the Me-EDT-TTF enantiomers. ${ }^{53}$ Accordingly, $(R)-2 a$ is dextrorotatory and $(S)-2 a$ is levorotatory, with specific optical rotation values of +47 and $-46 \mathrm{deg} \cdot \mathrm{mL} \cdot \mathrm{g}^{-1} \cdot \mathrm{dm}^{-1}\left([\alpha]_{589}{ }^{25}\right.$ in $\mathrm{CH}_{2} \mathrm{Cl}_{2}$, see the $\left.\mathrm{SI}\right)$, respectively. Moreover, this assignment was confirmed by the single crystal X-ray structure of $(S)$-1a.

The racemic and $(S)$ enantiomer of 1a have given single crystals for X-ray diffraction by slow evaporation from tetrahydrofuran solutions. The single crystals of $(S, S)$-1 $\mathbf{b}$ have been obtained by slow diffusion of diethyl ether into a solution of compound in tetrahydrofuran followed by evaporation. X-ray analysis shows for all the crystals one independent molecule in the unit cell of the monoclinic non-centrosymmetric space group $P 2_{1}$ (Figure 1$)$. In all the cases the molecules show disorder on the two amide groups whereas the racemic of 1a shows an extra disorder on the ethylene bridge, ensuring the presence of the two enantiomers in the asymmetric unit. The molecules pack within the crystals via hydrogen bonding between the amide units $\mathrm{NH} \cdots \mathrm{O}=\mathrm{C}$ of the same molecule and of neighboring molecules (Table S1 and Figure S1). Note the equatorial conformation of the methyl substituent in $(S)$ and $(\mathrm{rac})-\mathbf{1 a}$, while the two methyl groups in $(S, S)-\mathbf{1 b}$ lie in axial positions. DFT calculations on the DM-EDT-TTF donor shown that the axial and equatorial conformers are very close in energy, ${ }^{54}$ therefore the occurrence of one or the other in the solid state is very likely a consequence of the crystal packing. 

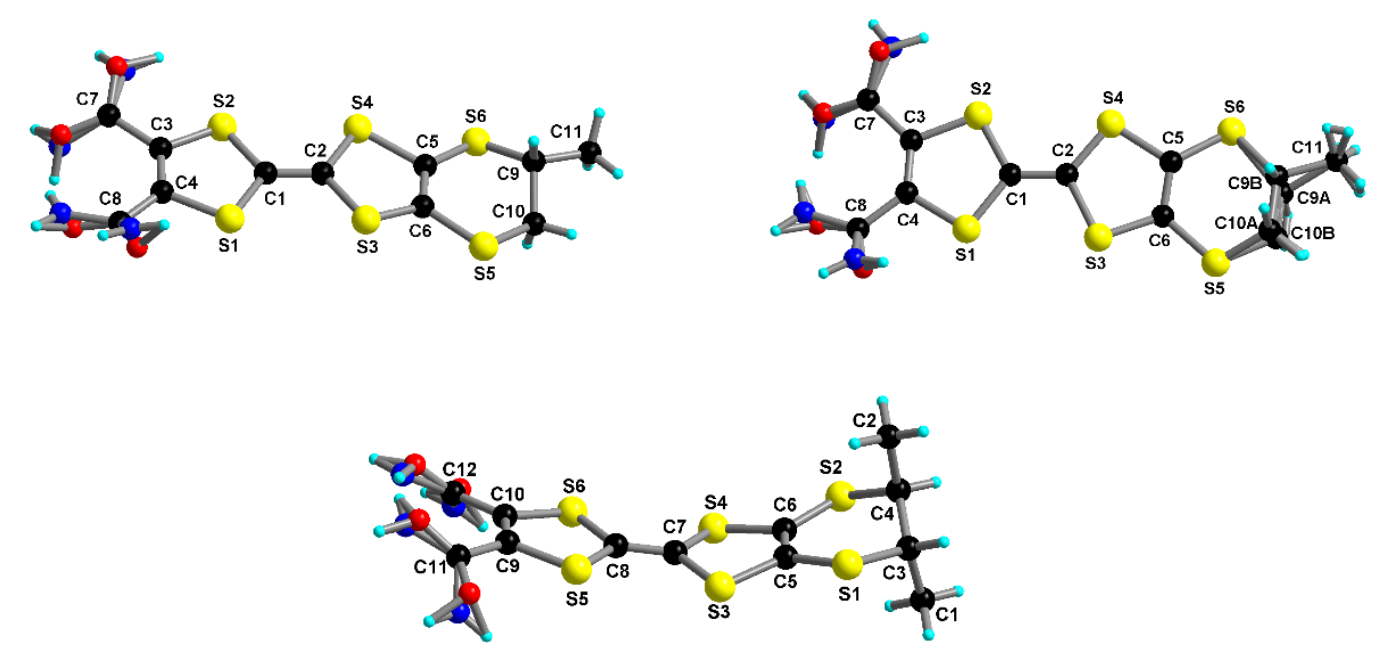

Figure 1. Molecular structures of (S)-1a (top, left), (rac)-1a (top, right) and (S,S)-1b (bottom) donors with atom labels.

\section{Radical cation salts}

Electrocrystallization of both enantiomers of $\mathbf{1 b}$, in a $1 / 1$ mixture of THF and 1,1,2-trichloroethane using $\left[\mathrm{NBu}_{4}\right] \mathrm{ClO}_{4}$ and $\left[\mathrm{NBu}_{4}\right] \mathrm{ReO}_{4}$ as supporting electrolytes, afforded the corresponding isostructural radical cation salts $[(S, S)-\mathbf{1 b}]_{2} \mathrm{XO}_{4}$ and $[(R, R)-\mathbf{1} \mathbf{b}]_{2} \mathrm{XO}_{4}(\mathrm{X}=\mathrm{Cl}, \mathrm{Re})$, respectively, which crystallized in the monoclinic $P 2_{1}$ space group. X-ray diffraction analysis of the single crystals shows four independent molecules in the unit cell, in different degrees of oxidation, and two anions for both $[\mathbf{1 b}]_{2} \mathrm{ClO}_{4}$ and $[\mathbf{1} \mathbf{b}]_{2} \mathrm{ReO}_{4}$ salts, giving thus a ratio of two donors for one anion. Within the four repeating units that give the parallel columns of TTFs we can distinguish two groups of donors, namely almost neutral (A and C) and mono-oxidized (B and D) (e.g. for [(S,S)-1 $\left.\mathbf{b}]_{2} \mathrm{ClO} \mathbf{O}_{4}\right)$. Somewhat stronger intramolecular $\mathrm{NH} \cdots \mathrm{O}=\mathrm{C}$ hydrogen bonding between the amide units have been observed in the neutral than in the oxidized donors, with values for the former similar to the ones in the neutral donor $(S, S)$-1b (Table 1). Similar oxidation degrees of the donors have been observed for the isostructural $[(R, R)$ $1]_{2} \mathrm{ReO}_{4}$. As also observed in most of the radical cation salts based on methylated EDT-TTF donors, ${ }^{48,53}$ the methyl groups adopt equatorial conformations, as a mean to maximize the orbital overlap between open shell species.

Table 1. Central C=C bond lengths $(\AA)$ and intramolecular $\mathrm{NH} \cdots \mathrm{O}=\mathrm{C}$ hydrogen bonding $(\AA)$ with the corresponding $\mathrm{N} \cdots \mathrm{O}=\mathrm{C}$ distances in $(S, S)-1 \mathrm{~b},[(S, S)-1 \mathrm{~b}]_{2} \mathrm{ClO}_{4}$ and $[(R, R)-1 \mathrm{~b}]_{2} \mathrm{ReO}_{4}$

\begin{tabular}{|c|c|c|c|c|c|c|c|}
\hline \multicolumn{3}{|c|}{$[(\mathrm{S}, \mathrm{S})-\mathbf{1} \mathbf{b}]_{2} \mathrm{ClO}_{4}$} & \multicolumn{3}{|c|}{$[(R, R)-\mathbf{1 b}]_{2} \mathrm{ReO}_{4}$} & \multicolumn{2}{|c|}{$(S, S)-\mathbf{1 b}$} \\
\hline Molecule & $C-C$ & $\begin{array}{l}\mathrm{NH} \cdots \mathrm{O}=\mathrm{C} \\
(\mathrm{N} \cdots \mathrm{O}=\mathrm{C})\end{array}$ & Molecule & $C-C$ & $\begin{array}{l}\mathrm{NH} \cdots \mathrm{O}=\mathrm{C} \\
(\mathrm{N} \cdots \mathrm{O}=\mathrm{C})\end{array}$ & $C-C$ & $\begin{array}{l}\mathrm{NH} \cdots \mathrm{O}=\mathrm{C} \\
(\mathrm{N} \cdots \mathrm{O}=\mathrm{C})\end{array}$ \\
\hline A & $1.3612(151)$ & $1.966(2.768)$ & A & $1.3261(130)$ & $1.955(2.755)$ & $1.3455(70)$ & $1.973(2.744)$ \\
\hline B & $1.3839(132)$ & $2.051(2.836)$ & B & $1.3693(119)$ & $1.975(2.782)$ & & \\
\hline C & $1.3244(132)$ & $1.933(2.753)$ & C & $1.3697(124)$ & $2.029(2.815)$ & & \\
\hline D & $1.3743(142)$ & 2.019 (2.807) & D & $1.3886(124)$ & 2.096 (2.879) & & \\
\hline
\end{tabular}

Strong lateral contacts through S...S interactions inferior to the sum of van der Waals radii give organic layers formed by $\mathbf{A}(\mathbf{D A})_{n} \mathbf{D}$ and $\mathbf{B}(\mathbf{C B})_{n} \mathbf{C}$ ribbons along the $b$ axis (Figure 2 ). The parallel columns of TTFs interact laterally 


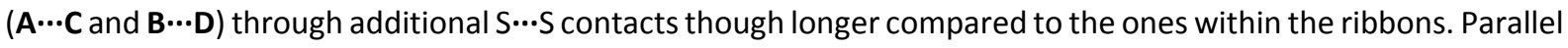
ribbons seem to close pack through intrastack S...S contacts giving head-to-head (h-to-h) dimers of $\mathbf{A B}$ and $\mathbf{C D}$ type within each column of TTFs (Figure S2). The strongest intra-dimer interaction is observed between the molecules of dimer $\mathbf{C D}$ whereas the shorter S...S contacts within $\mathbf{A B}$ are in the range of the inter-dimer distances (Table 2). The packing of the molecules in the crystal is of the $\beta^{\prime}$-type, similar to the one previously described for the achiral [EDT-TTF $\left.\left(\mathrm{CONH}_{2}\right)_{2}\right]_{2} \mathrm{X}\left(\mathrm{HSO}_{4}^{-}, \mathrm{ClO}_{4}{ }^{-}, \mathrm{ReO}_{4}{ }^{-}\right.$, and $\left.\mathrm{AsF}_{6}{ }^{-}\right)$salts. ${ }^{33}$ In contrast to [EDT-TTF $\left.(\mathrm{CONH})_{2}\right]_{2} \mathrm{ClO}_{4}$, the intra-stack interactions in $[(S, S)-\mathbf{1 b}]_{2} \mathrm{ClO}_{4}$ are much weaker, most probably because of the steric hindrance due to the methyl substituents of the ethylene bridge, and as consequence the interactions within the columns of donors are very weak. Therefore these interactions have been considered negligible and the solely considered HOMO $\cdots$ HOMO interactions are the lateral interactions between donors $\mathbf{B}$ with $\mathbf{D}$ and $\mathbf{A}$ with $\mathbf{C}$ (vide infra).

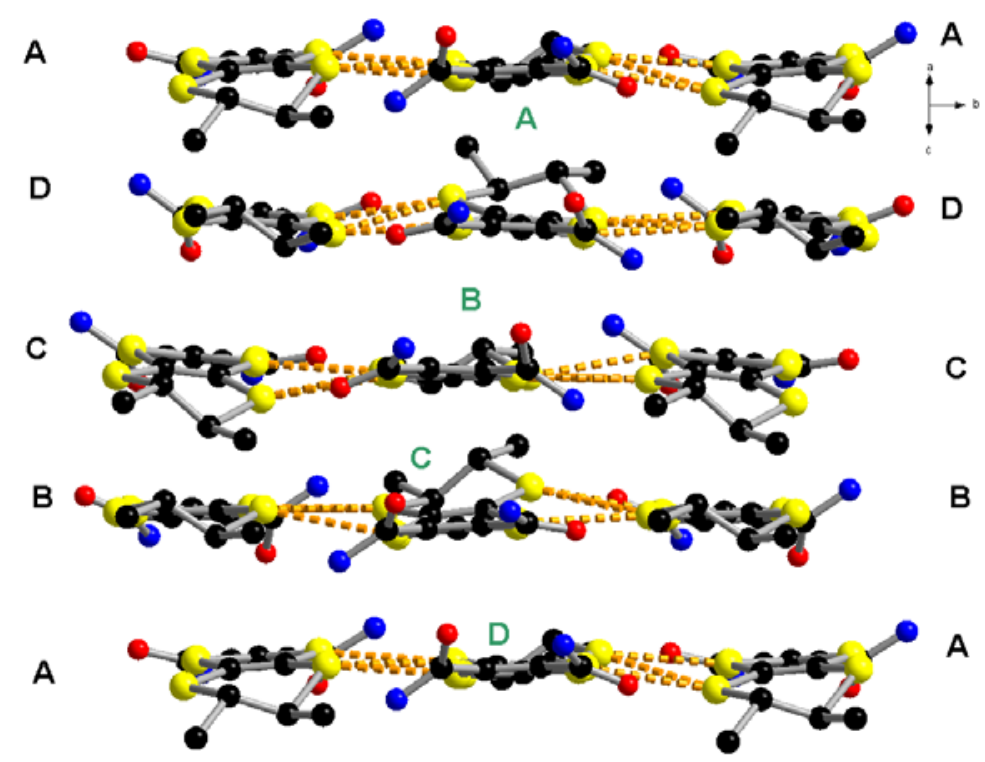

Figure 2. Packing in parallel stacks of the four types of molecules through short lateral S...S interactions along the $b$ axis in $[(\mathrm{S}, \mathrm{S})-\mathbf{1 b}]_{2} \mathrm{ClO}_{4}$.

Table 2. Short lateral and intra-stack $S \cdots S$ contacts in $[(S, S)-1 b]_{2} \mathrm{ClO}_{4}$ and $[(R, R)-1 b]_{2} \mathrm{ReO}_{4}$

\begin{tabular}{|c|c|c|c|c|c|c|c|}
\hline \multicolumn{4}{|c|}{$\mathrm{S} \cdots \mathrm{S}$ in $[(\mathrm{S}, \mathrm{S})-\mathbf{1 b}]_{2} \mathrm{ClO}_{4}$} & \multicolumn{4}{|c|}{$\mathrm{S} \cdots \mathrm{S}$ in $[(R, R)-1 \boldsymbol{b}]_{2} \mathrm{ReO}_{4}$} \\
\hline \multicolumn{2}{|c|}{ Lateral } & \multicolumn{2}{|c|}{ Intra-stack } & \multicolumn{2}{|c|}{ Lateral } & \multicolumn{2}{|c|}{ Intra-stack } \\
\hline \multirow[t]{6}{*}{$A$ and $\mathbf{C}$} & 3.284 & \multirow{4}{*}{$\begin{array}{l}\text { Intra-Dimer } \\
\text { (AB) }\end{array}$} & $3.780(6)$ & \multirow[t]{6}{*}{$\mathbf{A}$ and $\mathbf{C}$} & 3.286 & \multirow{5}{*}{$\begin{array}{l}\text { Intra-Dimer } \\
\text { (AD) }\end{array}$} & $3.772(5)$ \\
\hline & 3.394 & & $3.793(5)$ & & 3.405 & & $3.802(5)$ \\
\hline & 3.398 & & $3.808(5)$ & & 3.424 & & $3.813(4)$ \\
\hline & 3.422 & & $3.922(6)$ & & 3.429 & & $3.892(5)$ \\
\hline & 3.456 & & & & 3.450 & & $3.942(6)$ \\
\hline & 3.507 & & & & 3.498 & & \\
\hline \multirow[t]{9}{*}{ B and D } & 3.295 & \multirow{5}{*}{$\begin{array}{l}\text { Intra-Dimer } \\
\text { (CD) }\end{array}$} & $3.686(5)$ & \multirow[t]{6}{*}{ B and D } & 3.303 & \multirow{5}{*}{$\begin{array}{l}\text { Intra-Dimer } \\
\text { (BC) }\end{array}$} & $3.658(5)$ \\
\hline & 3.340 & & $3.671(6)$ & & 3.355 & & $3.697(4)$ \\
\hline & 3.377 & & $3.721(5)$ & & 3.367 & & $3.760(5)$ \\
\hline & 3.438 & & $3.765(6)$ & & 3.429 & & $3.744(4)$ \\
\hline & 3.441 & & & & 3.450 & & $3.926(6)$ \\
\hline & 3.469 & & & & 3.459 & & \\
\hline & & \multirow{3}{*}{$\begin{array}{l}\text { Inter-Dimers } \\
\text { (AB) } \cdots \text { (CD) }\end{array}$} & $3.798(6)$ & & & \multirow{3}{*}{$\begin{array}{l}\text { Inter-Dimers } \\
\text { (BC) } \cdots \text { (AD) }\end{array}$} & $3.864(5)$ \\
\hline & & & $3.879(5)$ & & & & $3.934(4)$ \\
\hline & & & $3.979(7)$ & & & & $3.960(5)$ \\
\hline
\end{tabular}


Besides lateral S $\cdots$ S contacts, the packing within the ribbons is strengthened by $\mathrm{NH} \cdots \mathrm{O}=\mathrm{C}$ hydrogen bonding between the amide units. Thus, different columns interact in the $a b$ plane as shown by the short $\mathrm{NH} \cdots \mathrm{O}=\mathrm{C}$ distances between molecules $\mathbf{A}$ and $\mathbf{D}$, and $\mathbf{B}$ and $\mathbf{C}$ (Table 3). Other inter-column interactions of $\mathrm{NH} \cdots \mathrm{O}=\mathrm{C}$

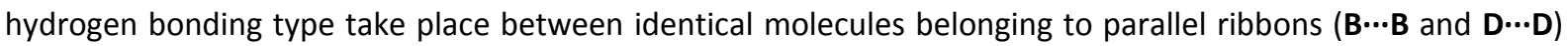
(Figure 3).

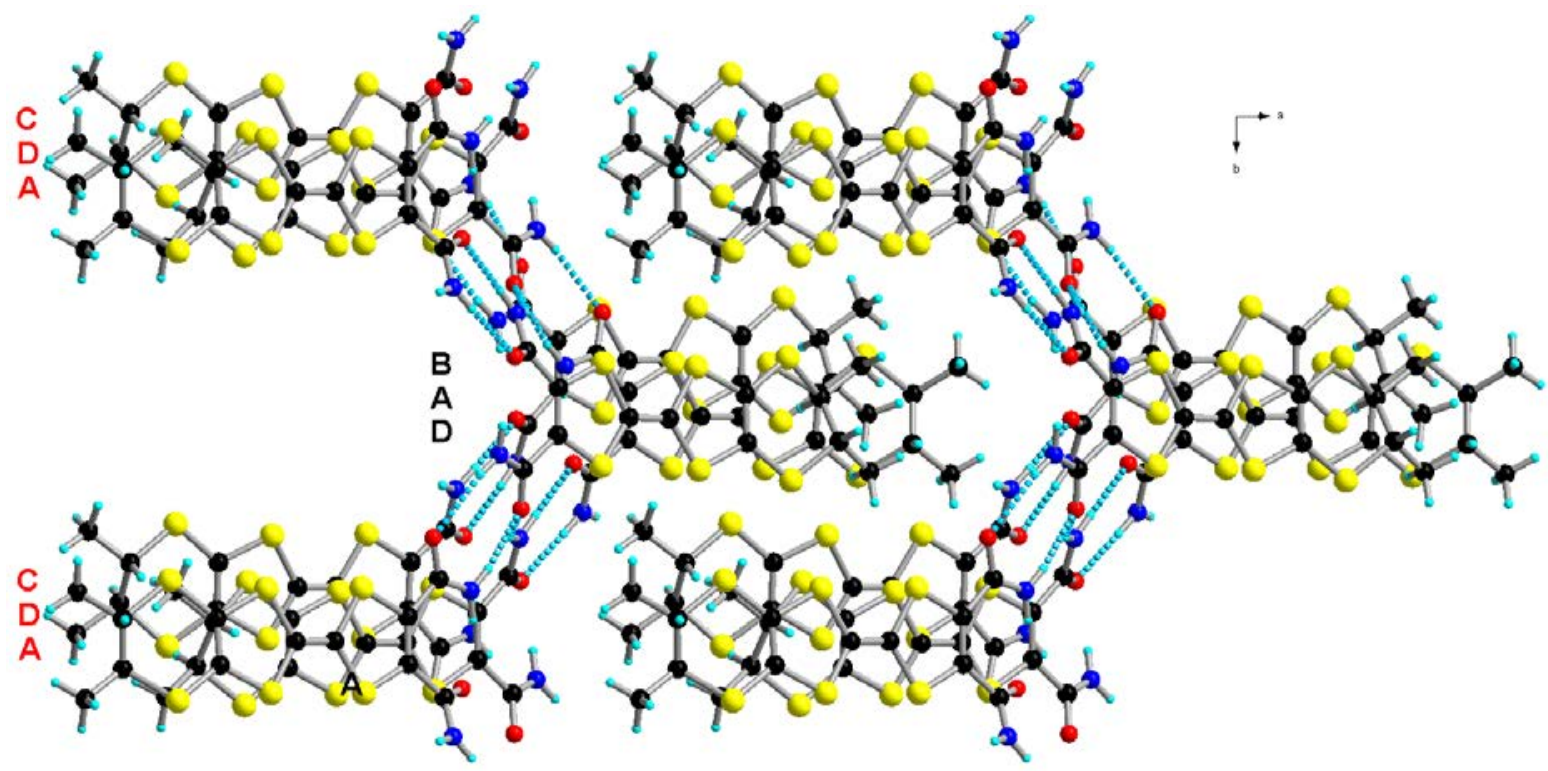

Figure 3. Intermolecular $\mathrm{NH} \cdots \mathrm{O}=\mathrm{C}$ hydrogen bonding between $\mathbf{A}$ and $\mathbf{D}$, and $\mathbf{B}$ and $\mathbf{C}$ molecules of neighboring stacks of $[(S, S)$ 1b] ${ }_{2} \mathrm{ClO}_{4}$.

Table 3. Intermolecular hydrogen bonding $(\AA) \mathrm{NH} \cdots \mathrm{O}=\mathrm{C}, \mathrm{NH} \cdots \mathrm{O}\left(\mathrm{XO}_{4}\right)$ and $\mathrm{CH} \cdots \mathrm{O}\left(\mathrm{XO}_{4}\right)$ in $[(S, S)-1 \mathrm{~b}]_{2} \mathrm{ClO}{ }_{4}$ and $[(R, R)-1 \mathrm{~b}]_{2} \mathrm{ReO}{ }_{4}$

\begin{tabular}{|c|c|c|c|c|c|}
\hline \multicolumn{3}{|c|}{$[(S, S)-\mathbf{1 b}]_{2} \mathrm{ClO}_{4}$} & \multicolumn{3}{|c|}{$[(R, R)-\mathbf{1} \mathbf{b}]_{2} \mathrm{ReO}_{4}$} \\
\hline $\mathrm{NH} \cdots \mathrm{O}=\mathrm{C}$ & $\mathrm{NH} \cdots \mathrm{O}\left(\mathrm{ClO}_{4}\right)$ & $\mathrm{CH} \cdots \mathrm{O}\left(\mathrm{ClO}_{4}\right)$ & $\mathrm{NH} \cdots \mathrm{O}=\mathrm{C}$ & $\mathrm{NH} \cdots \mathrm{O}\left(\mathrm{ReO}_{4}\right)$ & $\mathrm{CH} \cdots \mathrm{O}\left(\mathrm{ReO}_{4}\right)$ \\
\hline $\mathbf{A}$ and $\mathbf{D}$ & A & $\mathrm{Cl} 1$ & $\mathbf{A}$ and $\mathbf{C}$ & A & Re1 \\
\hline 2.064 & $2.613(\mathrm{Cl} 1)$ & $2.676(\mathbf{A})^{a}$ & 2.094 & 2.585 (Re1) & $2.430(\mathrm{~A})^{\mathrm{a}}$ \\
\hline 2.104 & $2.611(\mathrm{Cl} 1)$ & $2.705(\mathrm{~A})$ & 2.131 & 2.615 (Re1) & $2.856(\mathrm{~A})$ \\
\hline 2.109 & $2.109(\mathrm{Cl} 2)$ & $2.472(B)$ & 2.165 & $2.054(\operatorname{Re} 2)$ & \\
\hline \multirow[t]{2}{*}{2.311} & & 2.568 (B) & 2.296 & & \\
\hline & B & & & B & \\
\hline B and $\mathbf{C}$ & $2.611(\mathrm{Cl} 1)$ & $\mathrm{Cl} 2$ & B and D & 2.069 (Re1) & $\operatorname{Re} 2$ \\
\hline 2.047 & & 2.402 (C) & 2.051 & $2.667(\operatorname{Re} 2)$ & 2.575 (B) \\
\hline 2.083 & & $2.572(\mathrm{C})$ & 2.082 & $2.609(\mathrm{Re} 2)$ & $2.420(\mathrm{C})$ \\
\hline 2.133 & & 2.450 (D) & 2.133 & & \\
\hline \multirow[t]{2}{*}{2.240} & $\mathrm{C}$ & 2.715 (D) & 2.228 & C & \\
\hline & $2.142(\mathrm{Cl} 1)$ & & & 2.649 (Re1) & \\
\hline $\mathbf{B}$ and $\mathbf{B}$ & $2.644(\mathrm{Cl} 2)$ & & $\mathbf{C}$ and $\mathbf{C}$ & $2.567(\mathrm{Re} 2)$ & \\
\hline 2.194 & $2.713(\mathrm{Cl} 2)$ & & 2.320 & & \\
\hline D and $\mathbf{D}$ & D & & D and D & D & \\
\hline 2.252 & $2.559(\mathrm{Cl} 2)$ & & 2.290 & 2.414 (Re1) & \\
\hline
\end{tabular}

${ }^{a} \mathrm{CH}($ bridge $) \cdots \mathrm{O}\left(\mathrm{XO}_{4}\right)$

All four types of molecules are involved in intermolecular hydrogen bonding of the amide units with the anions $\left(\mathrm{NH} \cdots \mathrm{O}\left(\mathrm{XO}_{4}\right)\right)$ with values ranging from $2.109 \AA$ to $2.713 \AA$. Thus, one of the anions $(\mathrm{Cl} 1)$ is interacting with 
molecules A, B and $\mathbf{C}$, whereas the other one $(\mathrm{Cl} 2)$ with molecules $\mathbf{A}, \mathbf{C}$ and $\mathbf{D}$. The anions are involved in less strong interactions with the protons of the ethylene bridge and the methyl units $\left(\mathrm{CH} \cdots \mathrm{O}\left(\mathrm{XO}_{4}\right)\right)$, one interacting with molecules $\mathbf{A}$ and $\mathbf{B}$ whereas the other one with $\mathbf{C}$ and $\mathbf{D}$ (Table 3 and Figure 4).
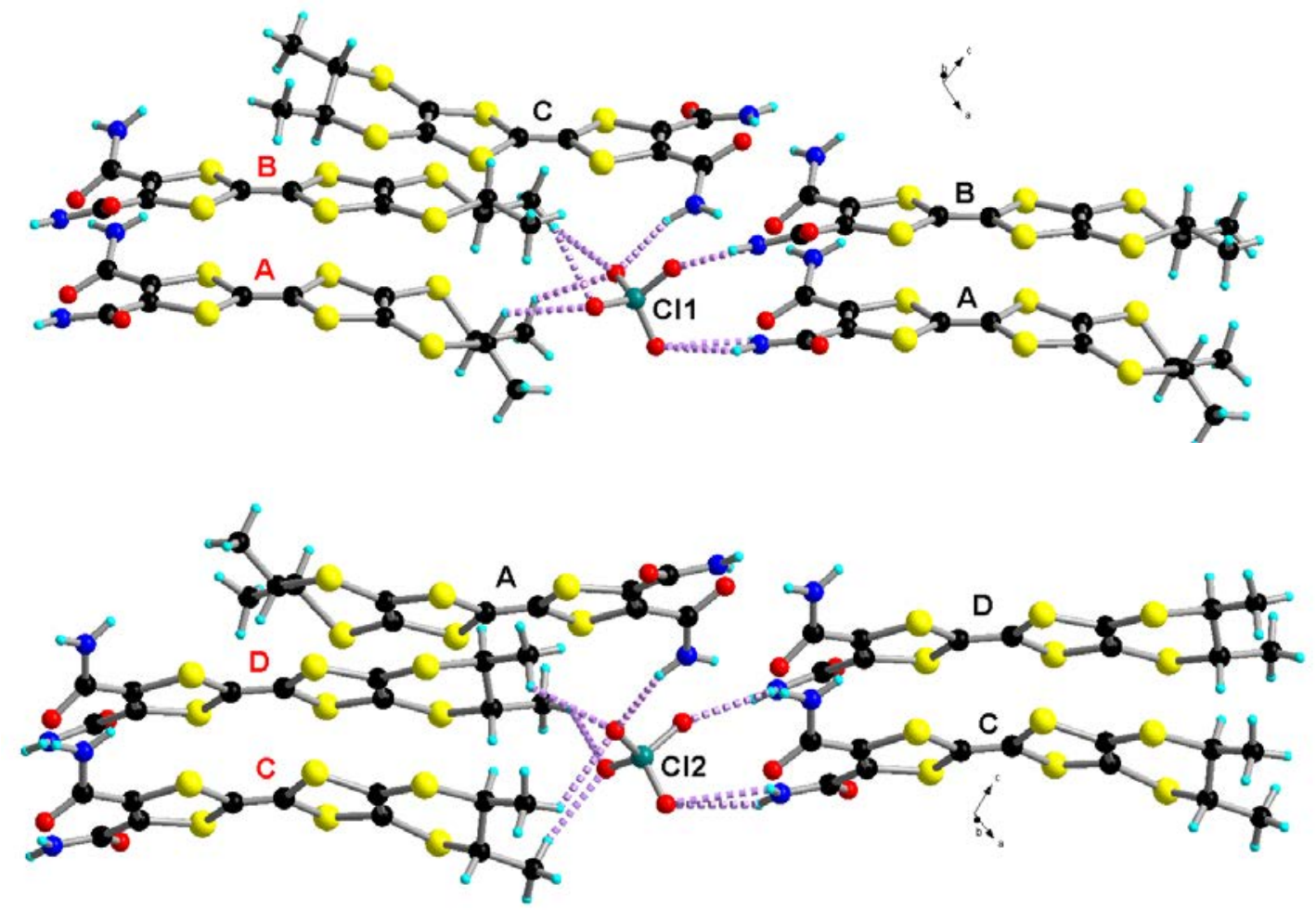

Figure 4. Intermolecular hydrogen bonding of the anions with the amide units (molecules labelled in black) and with the protons of the ethylene bridge and the methyl groups (molecules labelled in red) in $[(S, S)-\mathbf{1 b}]_{2} \mathrm{ClO}_{4}$.

For comparison all tables contain as well data of $[(R, R)-\mathbf{1 b}]_{2} \mathrm{ReO}_{4}$ from which small differences with the $\mathrm{ClO}_{4}$ counterpart could be noted such as average shorter hydrogen bonds for the $\mathrm{ReO}_{4}{ }^{-}$salt (Table 3 and Figures S3 and S4), while S...S distances are in the same range for all four radical cation salts ( Table 2).

Electron transport properties and band structure calculations of the radical cation salts

Single crystal temperature dependent resistivity measurements of the radical cation salts $\left[(S, S)-\mathbf{1 b}_{2} \mathrm{ClO}_{4}\right.$ and $[(R, R)-\mathbf{1 b}]_{2} \mathrm{ReO}_{4}$ show semiconducting behavior, with room temperature conductivities of the order of $510^{-5} \mathrm{~S}$ $\mathrm{cm}^{-1}$ and activation energies $\mathrm{E}_{\mathrm{a}} \approx 3000 \mathrm{~K}$ (Figure 5), as could be expected when considering the observed charge

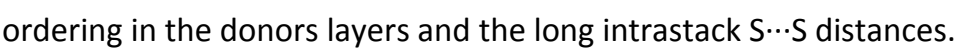




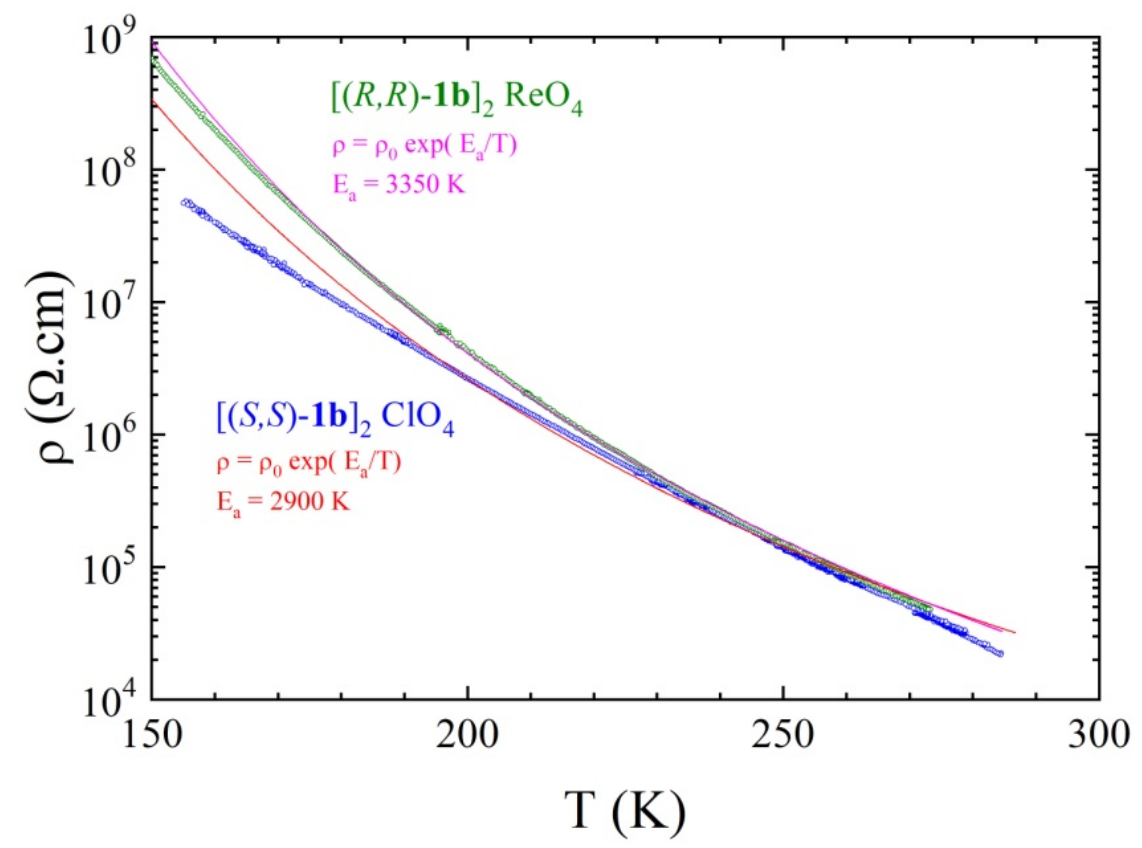

Figure 5. Temperature dependence of the electrical resistivity $\rho$ for single crystals of $[(S, S)-\mathbf{1 b}]_{2} \mathrm{ClO}_{4}$ (blue) and $[(R, R)-\mathbf{1 b}]_{2} R e \mathrm{O}_{4}$ (green). The continuous lines are the fit giving the activation energies.

The donor layers of $[\mathbf{1 b}]_{2}\left(\mathrm{XO}_{4}\right)(\mathrm{X}=\mathrm{Cl}, \mathrm{Re})$ contain parallel chains along $\mathrm{c}$ built from four symmetry non-equivalent donors ( $\mathbf{A}$ to $\mathbf{D}$ in Figure 6). The repeat unit of the layer contains two of these $\mathbf{A B C D}$ chains in the case of $[(S, S)$ 1b] ${ }_{2} \mathrm{ClO}_{4}$. The four donors exhibit different central $\mathrm{C}=\mathrm{C}$ bond lengths ranging from 1.324 to $1.384 \AA$ but as shown in Figure 7c the HOMO levels clearly fall into two separate groups, $(\mathbf{A}, \mathbf{C})$ and $(\mathbf{B}, \mathbf{D})$, thus suggesting different oxidation states for the two groups.

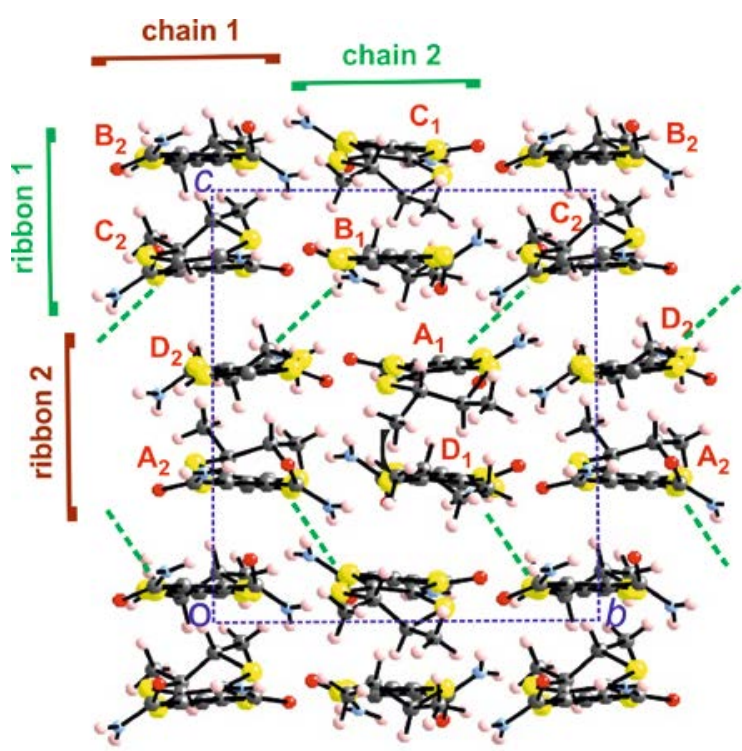

Figure 6. Donor layer of the for $[(S, S)-\mathbf{1} \mathbf{b}]_{2} \mathrm{ClO}_{4}$ salt . The four symmetry non-equivalent donor molecules are labelled $\mathbf{A}$ to $\mathbf{D}$. The green dashed lines denote the only HOMO $\cdots$ HOMO interactions that are not negligible (see text). 
There are several short $S \cdots S$ contacts both within the chain and between the chains. However, because of the relatively large energy difference, the interaction between HOMOs of the two different groups will be weak. As shown in Figure 7b where the band structure of an individual chain along $c$ is reported, the two pairs of HOMOs lead to two clearly separated pairs of bands which are only weakly dispersive $(\sim 0.05 \mathrm{eV})$. This clearly indicates weak interactions within the chains which is easily understandable because the donors of the two types alternate along the chain. Along the interchain direction the S $\cdots S$ contacts may be as short as 3.3-3.5 $\AA$, especially among pairs of donors at the same level in the $b$-direction (i.e., $B_{1} \cdots C_{2}, B_{2} \cdots C_{1}$, etc.). However all of these contacts are between donors of different groups and, again, the HOMO $\cdots \mathrm{HOMO}$ interactions are very weak. Other interchain interactions may occur between pairs of donors at different levels along the $c$-direction. However, because of the bulky substituents, those between donors of the same type (i.e. $A_{1} \ldots A_{2}, B_{1} \ldots B_{2}$, etc.) are not associated with

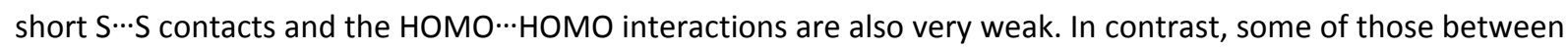
different pairs of donors of the same group (i.e., $A_{1} \cdots C_{2}, D_{1} \cdots B_{2}$, etc.) are associated with both relatively short $S \cdots S$ contacts and HOMOs of similar energy. These are the only interactions which can provide a clear electronic connection between HOMOs of different donors (see the green dashed lines in Figure 6). However, as it can be seen in Figure 6, only half of these contacts are effective because the bulky substituents induce long distances in the other half of these contacts (for instance, the interaction of $B_{1}$ with the $D_{2}$ donor at the left is associated with short $S \cdots S$ contacts but that with the $D_{2}$ donor at the right is not associated with short $S \cdots S$ contacts).

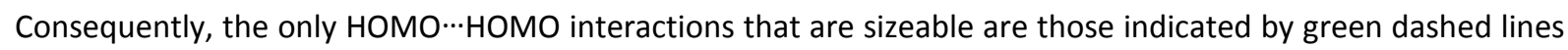
in Figure 6. Their strength can be estimated from the so-called | $\beta_{\text {номо-номо }}$ interaction energies. ${ }^{55}$ Those for the $A_{1} \cdots C_{2}$ (or $A_{2} \cdots C_{1}$ ) and $D_{1} \cdots B_{2}$ (or $D_{2} \cdots B_{1}$ ) interactions are calculated to be 0.1059 and $0.071 \mathrm{eV}$, respectively. These values are non-negligible, but correspond to only moderate interactions. ${ }^{56,49,33}$

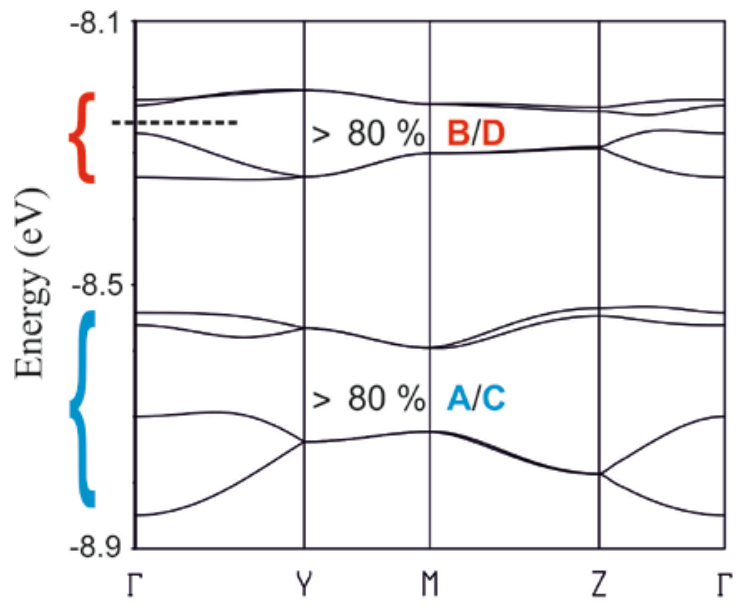

(a)

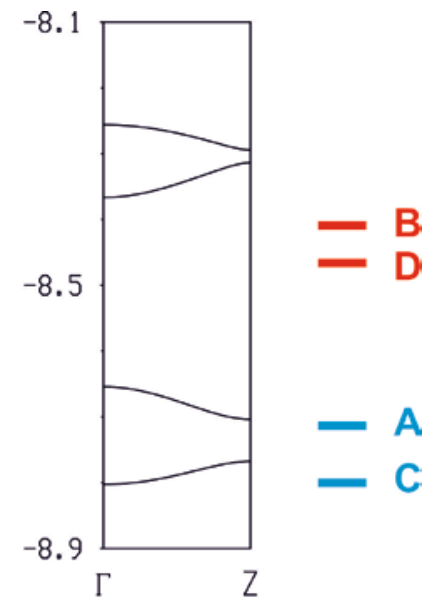

(b) (c)

Figure 7. Extended Hückel band structure for the donor layers (a) and for one of the chains along the $c$-direction (b) for the $[(S, S)-\mathbf{1 b}]_{2} \mathrm{ClO}_{4}$ salt. $\Gamma=(0,0), Y=\left(b^{*} / 2,0\right), Z=\left(0, c^{*} / 2\right)$ and $\mathrm{M}=\left(b^{*} / 2, c^{*} / 2\right)$ and the dashed line refers to the Fermi level assuming double occupation of the levels. (c) HOMO levels of the four donors. 
A look at Figure 6 clearly shows that there is not a continuous path of such non negligible HOMO $\cdots \mathrm{HOMO}$ interactions along the solid. Consequently, whatever the strength of these interactions might be, the band dispersion must be weak. The calculated band structure for the donor layers in $[(S, S)-\mathbf{1} \mathbf{b}]_{2} \mathrm{ClO}_{4}$ (Figure 7a) shows that this is indeed the case. This is specially observed for the four upper bands which are those associated with the holes. Analysis of the crystal orbitals associated with the four upper bands shows that these levels are more than $80 \%$ concentrated in the HOMOs of the $\mathbf{B}$ and $\mathbf{D}$ donors whereas those of the four bottom bands are more than $80 \%$ concentrated in the HOMOs of the $\mathbf{A}$ and $\mathbf{C}$ donors. Thus $\mathbf{A}$ and $\mathbf{C}$ should be formally considered as neutral whereas $\mathbf{B}$ and $\mathbf{D}$ are formally mono-cations. Exactly the same situation is found both for the topology of the band structure and nature of the bands for the four salts reported here (for instance see the calculated band structure for the $[(R, R)-\mathbf{1} \mathbf{b}]_{2} \mathrm{ClO}_{4}$ and for $[(R, R)-\mathbf{1 b}]_{2} \mathrm{ReO}_{4}$ salts in the supplementary information).

The repeat unit of the layer contains two $A B C D$ chains so that the number of holes per repeat unit is four. Since there is a band gap separating the two pairs of upper bands it may be suggested that $[(S, S)-\mathbf{1 b}]_{2} \mathrm{ClO}_{4}$ is an intrinsic (i.e. regular band gap) semiconductor. However, since the four upper bands are quite narrow and thus the electronic repulsions will favor an electronic localization, the system may also be a Mott insulator. Although both situations are associated with an activated conductivity, the two possibilities correspond to very different physical situations. In the first case, all electrons are paired so that the four electrons of the $\mathbf{B}$ and $\mathbf{D}$ donors must be localized in the $B_{1} \cdots D_{2}$ and $B_{2} \cdots D_{1}$ pairs with the electrons of the $\mathbf{B}$ and $\mathbf{D}$ donors paired because of the dashed green interaction. This corresponds to an intrinsic semiconductor. In contrast, the second possibility is associated with a series of unpaired electrons located on the four $\mathbf{B}$ and $\mathbf{D}$ donors interacting more weakly than in the previous case and thus being able to lead to different magnetic states depending on the different coupling constants. One of the factors distinguishing between the band gap and Mott situations is the strength of the green dashed interaction; the intrinsic semiconductor situation is favored when this interaction increases.

In order to discriminate among the two possibilities we have carried out first-principles density functional theory (DFT) calculations for both the intrinsic semiconductor and several localized configurations for the $[(S, S)-\mathbf{1 b}]_{2} \mathrm{ClO}_{4}$ salt. We have found four different localized configurations which may be schematically described as in Figure 8 , which is a simplified representation of Figure 6 where every type of donor is represented by a solid line with a different color: blue (A), black (B), green (C) and red (D). The length of the arrows indicates the magnitude of the spin density for the different donors. The FM state is a ferromagnetic state with four spin-up spins per repeat unit cell (see Figure S7 for the band structure). According to these calculations the unpaired spins (and thus the holes) are mostly located on the $\mathbf{B}$ and $\mathbf{D}(71 \%)$. However there is a substantial delocalization towards the neighboring $\mathbf{A}$ and $\mathbf{C}$ donors (29\%). As a matter of fact, when the density of states of the intrinsic semiconductor given by the DFT calculations is analyzed, the hole distribution is very similar to that of the FM state, $68 \%$ are located in the $\mathbf{B}$ and $\mathbf{D}$ donors and thus $32 \%$ on the $\mathbf{A}$ and $\mathbf{C}$ donors. Thus these ferromagnetic and intrinsic semiconductor states provide a textbook example of the difference between localized and delocalized systems with practically the same concentration of holes per molecule. Note that the band structure of the intrinsic semiconductor as given by DFT (Figure 9a) shares all features of the extended Hückel one (Figure 7a); in particular a relatively small gap is found in both cases along the $\Gamma$ to $Z$ direction. As shown in Table 4 , the ferromagnetic 
state is $17 \mathrm{meV}$ per unit cell more stable than the intrinsic semiconductor thus pointing out the preference for localized holes in this salt and the weakness of the dashed green interactions in Figure 6.

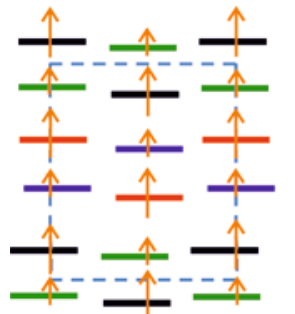

FM

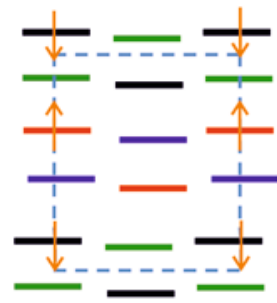

AF 2

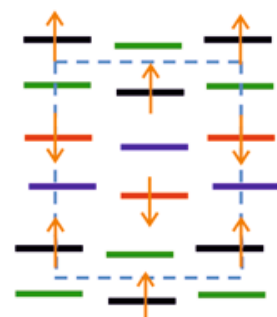

AF 1

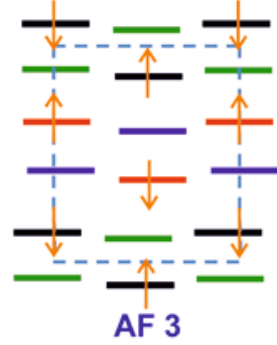

donor D -

Figure 8. Schematic representation of the donor layer in Figure 6 where the different localized states (FM, AF 1, AF 2 and AF 3) obtained for the $[(S, S)-\mathbf{1} \mathbf{b}]_{2} \mathrm{ClO}_{4}$ salt through spin-polarized DFT calculations are shown. Every type of donor is represented by a solid line with a different color: blue (A), black (B), green (C) and red (D). The length of the arrows indicates schematically the magnitude of the spin density for the different donors.

The previous result suggests that localized states where some of the magnetic couplings turn out to be antiferromagnetic could be more stable. The two most stable states that we have found are those labelled AF 1 and AF $\mathbf{3}$ in Figure 8. In these cases the holes are completely localized in donors $\mathbf{B}$ and $\mathbf{D}$ and donors $\mathbf{A}$ and $\mathbf{C}$ are neutral. There are three types of magnetic coupling in these states: (i) indirect B-D coupling through $\mathbf{A}$ and $\mathbf{C}$ donors along the chains (c-direction), (ii) direct B-B and D-D coupling along the B/C or A/D ribbons along $b$ (see Figure 6), and (iii) direct B-D inter-ribbons coupling. States AF 1 and AF 3 exhibit antiferromagnetic coupling along the chains (four interactions per unit cell) but they differ in the direct couplings (inter- and intra-ribbon). Whereas in AF 1 the intra-ribbon interactions (4 per unit cell) are ferromagnetic and the inter-ribbon (2 per unit cell) are antiferromagnetic, in AF 3 occurs just the opposite. As shown in Table 4, both AF 1 and AF 3 are substantially more stable than the intrinsic semiconductor. State AF 3 with the maximum of antiferromagnetic interactions is marginally more stable. As shown in Figure 9 both AF 1 and AF 3 exhibit larger gaps than the intrinsic semiconductor so that they are more stable but less conductive than the intrinsic semiconductor.

Table 4. DFT relative energy differences (meV/unit cell) for the delocalized intrinsic semiconductor and the different localized states in Figure 7

\begin{tabular}{|l|l|}
\hline State & Energy (meV/unit cell) \\
\hline Intrinsic semiconductor & 46 \\
\hline FM & 29 \\
\hline AF 1 & 4 \\
\hline AF 2 & 30 \\
\hline AF 3 & 0 \\
\hline
\end{tabular}


a)

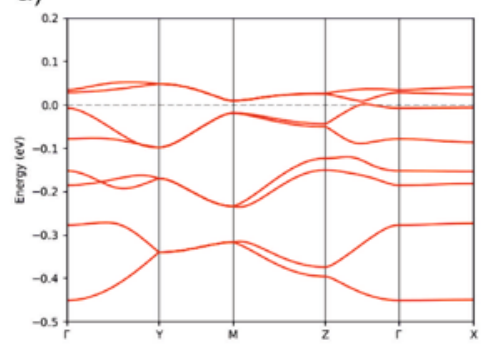

b)

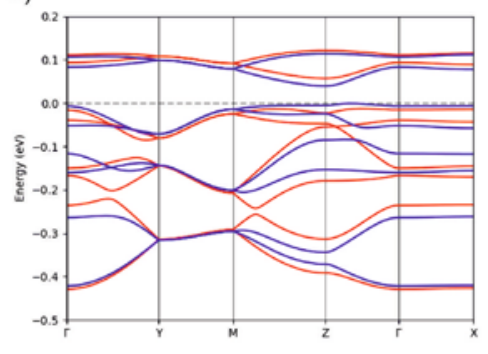

c)

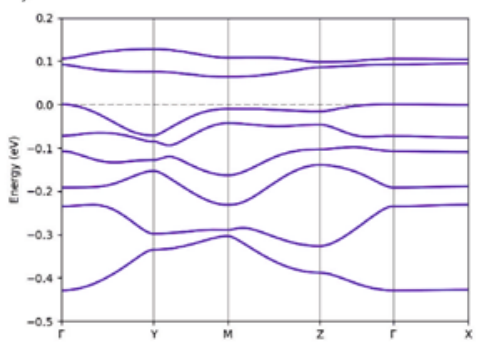

Figure 9. DFT band structures for the intrinsic semiconductor (a) AF 1 (b) and AF 3 (c) states for the $[(S, S)-1 \mathbf{b}]_{2} \mathrm{ClO}_{4}$ salt. $\Gamma=$ $(0,0,0), Y=\left(0, b^{*} / 2,0\right), Z=\left(0,0, c^{*} / 2\right), M=\left(0, b^{*} / 2, c^{*} / 2\right)$ and $X\left(a^{*} / 2,0,0\right)$. The dashed line refers to the highest occupied level in all cases. All levels are doubly filled in (a). Spin up and spin-down bands are shown in red and blue, respectively in (b) and (c). The spin-up and spin-down bands are identical although located in spatially different but equivalent sites in (c) so that only the blue bands are visible.

It is interesting to note that the state labelled AF 2 in Figure 8 is also more stable than the intrinsic semiconductor (see Figure S8 for the band structure). From the physical viewpoint this state contains alternate chains with delocalized and localized electrons with antiferromagnetic coupling along the chains. This state is degenerate with another state that can be obtained by swapping the localized and delocalized electrons on the two chains. The stability of these two states is intermediate between that of the intrinsic semiconductor and the AF 1 and AF 3 fully localized states. Again, this result confirms the tendency to the localization along the chains in this salt. We thus conclude that for $[(S, S)-\mathbf{1} \mathbf{b}]_{2} \mathrm{ClO}_{4}$ and most likely the other three salts will behave as localized semiconductors, in agreement with the single crystal resistivity data (vide supra).

\section{CONCLUSIONS}

Chiral mono- and dimethylated EDT-TTF primary diamide derivatives $\mathbf{1 a}$ and $\mathbf{1} \mathbf{b}$ have been synthesized by direct amidation of the corresponding diester precursors and their solid state structures determined by single crystal X-ray diffraction. The crystal packing is mainly driven by the interplay between the intra- and intermolecular $\mathrm{NH} \cdots \mathrm{O}=\mathrm{C}$ hydrogen bonding and intermolecular $\mathrm{S} \cdots \mathrm{S}$ interactions. Crystalline isostructural mixed valence radical cation salts have been obtained by electrocrystallization with the enantiopure donor $\mathbf{1 b}$ and $\mathrm{ClO}_{4}{ }^{-}$and $\mathrm{ReO}_{4}{ }^{-}$ monoanions. According to the single crystal X-ray analysis there are four independent donor molecules and two anions in the asymmetric unit, with the positive charge unequally distributed, two TTF being essentially neutral and the two other in the mono-oxidized state. In the organic layers there is formation of parallel columns of donors with formation of weak dimers, between charge rich and charge poor molecules, laterally shifted one to the other, a packing reminiscent of $\beta^{\prime}$-phases. However, both intrastack and interstack TTF $\cdots$ TTF transfer integral energies are relatively small, leading to weak dispersive energy bands, indicative of a band gap semiconductor or Mott insulator, according to tight-binding band structure calculations. Single crystal resistivity measurements on $[(S, S)-\mathbf{1 b}]_{2} \mathrm{ClO}_{4}$ and $[(R, R)-\mathbf{1 b}]_{2} \mathrm{ReO}_{4}$ show indeed semiconducting behavior with room temperature conductivity values of $510^{-5} \mathrm{~S} \mathrm{~cm}^{-1}$ and high activation energies. First-principles DFT calculations for both the intrinsic semiconductor and several spin localized configurations allow to conclude that the enantiopure salts described herein are localized semiconductors. These first examples of chiral methylated EDT-TTF donors and conducting radical cation salts demonstrate the rich opportunities opened by the association of hydrogen 
bonding donor/acceptor groups and chirality towards the preparation of chiral materials in which the anions play an active role through the establishment of strong intermolecular TTF-amide $\cdots$ anion hydrogen bonding.

\section{EXPERIMENTAL SECTION}

\section{Materials and methods}

Commercially available reagents and solvents were used as received unless otherwise specified. 1,1,2trichloroethane and THF for electrocrystallization were used freshly distilled and purified by passage through activated alumina columns using a solvent purification system, respectively. All other reagents were used as received unless otherwise noted. Nuclear magnetic resonance spectra were recorded on a Bruker Avance DRX 300 spectrometer operating at $300 \mathrm{MHz}$ for ${ }^{1} \mathrm{H}$ and $75 \mathrm{MHz}$ for ${ }^{13} \mathrm{C}$. Chemical shifts are expressed in parts per million (ppm) downfield from external TMS. The following abbreviations are used: s, singlet; m, multiplet. MALDITOF MS spectra were recorded on Bruker Biflex-IIITM apparatus, equipped with a $337 \mathrm{~nm} \mathrm{~N}_{2}$ laser and MS-EI spectra on a double-focusing magnetic sector mass spectrometer Jeol JMS-700. Elemental analyses were recorded using Flash 2000 Fisher Scientific Thermo Electron analyzer.

\section{Syntheses}

(rac)-2-(5-methyl-5,6-dihydro-[1,3]dithiolo[4,5-b][1,4]dithiin-2-ylidene)-1,3-dithiole-4,5-dicarboxamide (rac)-1a To a solution of $(\mathrm{rac})-2 \mathrm{a}^{53}(200 \mathrm{mg}, 0.47 \mathrm{mmol})$ in $50 \mathrm{ml}$ of acetonitrile was added an excess of aqueous $\mathrm{NH}_{3}(10$ $\mathrm{ml}$ ) and the mixture stirred at r.t. for 24 hours. The formed solid was filtered and washed with acetonitrile and acetone to afford a dark mauve solid (130 mg, $70 \%) .{ }^{1} \mathrm{H}$ NMR (300 MHz, DMSO): $\delta 8.19$ (d, J = 72.8 Hz, 4H, NH 2 ), 3.85-3.78 (m, 1H, CH), 3.38 (dd, J = 13.2, 3.0 Hz, 1H, $-\mathrm{SCH}_{2} \mathrm{CH}-$ ), 3.18 (dd, J = 13.3, $6.9 \mathrm{~Hz}, 1 \mathrm{H},-\mathrm{SCH}_{2} \mathrm{CH}-$ ), 1.39 (d, $\left.\mathrm{J}=6.7 \mathrm{~Hz}, 3 \mathrm{H}, \mathrm{CH}_{3}\right) .{ }^{13} \mathrm{C}$ NMR $(75 \mathrm{MHz}$, DMSO) $\delta \mathrm{ppm}: 160.56(\mathrm{C}=\mathrm{O}), 133.22,113.35,111.87,111.33,105.95$, (C=C), 38.27 (S-CH), $35.89\left(\mathrm{CH}_{2}\right), 20.57\left(\mathrm{CH}_{3}\right) . \mathrm{MS}(\mathrm{EI}) \mathrm{m} / \mathrm{z}: 393.91\left(\mathrm{M}_{\mathrm{th}}=393.90\right)$. Elemental analysis calcld. (\%) for $\mathrm{C}_{11} \mathrm{H}_{10} \mathrm{~N}_{2} \mathrm{O}_{2} \mathrm{~S}_{6}$ : C 33.48; H 2.55; N 7.10; O 8.11; S 48.75. Found: C 33.64; H 2.41; N 7.23; O 8.08; S 48.83.

(S)-2-(5-methyl-5,6-dihydro-[1,3]dithiolo[4,5-b][1,4]dithiin-2-ylidene)-1,3-dithiole-4,5-dicarboxamide (S)-1a and (R)-2-(5-methyl-5,6-dihydro-[1,3]dithiolo[4,5-b][1,4]dithiin-2-ylidene)-1,3-dithiole-4,5-dicarboxamide (R)-1a The same synthetic procedure was followed as for the racemic mixture starting from $(S)-\mathbf{2 a}$ and $(R)-\mathbf{2 a}$, respectively.

2-((S,S)-5,6-dimethyl-5,6-dihydro-[1,3]dithiolo[4,5-b][1,4]dithiin-2-ylidene)-1,3-dithiole-4,5-dicarboxamide [(S,S)1b]

To a solution of $(S, S)-2 \mathbf{b}^{48}(0.3 \mathrm{~g}, 0.68 \mathrm{mmol})$ in $50 \mathrm{ml}$ of acetonitrile was added an excess of aqueous $\mathrm{NH}_{3}(10 \mathrm{ml})$ and the mixture stirred at r.t. for 24 hours. The formed solid was filtered and washed with acetonitrile and acetone to afford a dark mauve solid (0.178 g, $60 \%$ ). ${ }^{1} \mathrm{H}$ NMR (300 MHz, DMSO) $\delta 8.31$ (s, 2H), 3.53 (m, J=5.3 $\mathrm{Hz}, 2 \mathrm{H}), 1.33$ (m, J = 6.1 Hz, 6H). ${ }^{13} \mathrm{C}$ NMR (75 MHz, DMSO) $\delta 160.59,133.19,111.25,110.50,105.53,42.87,22.10$. MS (MALDI-TOF) m/z: $407.6\left(\mathrm{M}_{\mathrm{th}}=407.92\right)$. Elemental analysis calcd. (\%) for $\mathrm{C}_{12} \mathrm{H}_{12} \mathrm{~N}_{2} \mathrm{O}_{2} \mathrm{~S}_{6}: \mathrm{C} 35.27, \mathrm{H} 2.96, \mathrm{~N}$ 6.86, S 47.08; found: C 35.57, H 2.97, N 6.76, S 47.12. 
2-((R,R)-5,6-dimethyl-5,6-dihydro-[1,3]dithiolo[4,5-b][1,4]dithiin-2-ylidene)-1,3-dithiole-4,5-dicarboxamide $[(R, R)-1 b]$

The same synthetic procedure was followed as for the $(S, S)$ enantiomer starting from $(R, R)-\mathbf{2 b}$.

\section{Electrocrystallization}

$[(S, S)-\mathbf{1 b}]_{2} \mathrm{ClO}_{4} .21 \mathrm{mg}$ of $\left[\mathrm{NBu}_{4}\right] \mathrm{ClO}_{4}$ were dissolved in $6 \mathrm{~mL}$ of THF/1,1,2-trichloroethane (1/1) and the solution was poured into the cathodic compartment of the electrocrystallization cell. The anodic chamber was filled with $5 \mathrm{mg}$ of $[(S, S)$-1] dissolved in $6 \mathrm{~mL}$ of THF/1,1,2-trichloroethane (1/1). Single crystals of the salt were grown at 20 ${ }^{\circ} \mathrm{C}$ over a period of 5 days on a platinum wire electrode by applying a constant current of $1 \mu \mathrm{A}$. Black needles were obtained on the electrode and in solution.

$[(R, R)-\mathbf{1} \boldsymbol{b}]_{2} \mathrm{ClO}_{4}$. Same conditions and amounts as previously described were employed.

$[(S, S)-1 b]_{2} R O_{4} .30 \mathrm{mg}$ of $\left[\mathrm{NBu}_{4}\right] \mathrm{ReO}_{4}$ were dissolved in $6 \mathrm{~mL}$ of THF/1,1,2-trichloroethane (1/1) and the solution was poured into the cathodic compartment of the electrocrystallization cell. The anodic chamber was filled with $5 \mathrm{mg}$ of $[(S, S)-1 \mathbf{b}]$ dissolved in $6 \mathrm{~mL}$ of THF/1,1,2-trichloroethane (1/1). Single crystals of the salt were grown at $20{ }^{\circ} \mathrm{C}$ over a period of 7 days on a platinum wire electrode by applying a constant current of $0.5 \mu \mathrm{A}$ for 2 days followed by $1 \mu \mathrm{A}$ for 5 days. Black needles were obtained on the electrode and in solution.

$[(R, R)-1 b]_{2} \mathrm{ReO}_{4}$. Same conditions and amounts as previously described were employed.

\section{Single Crystal X-ray Diffraction}

X-ray single-crystal diffraction data were collected on an Agilent SuperNova diffractometer equipped with Atlas CCD detector and mirror monochromated micro-focus Cu- $K_{\alpha}$ radiation $(\lambda=1.54184 \AA$ ) and on a Nonius Kappa CCD diffractometer using graphite-monochromated MoK $K_{\alpha}$ radiation $(\lambda=0.71073 \AA$ ). The structure was solved by direct methods, expanded and refined on $\mathrm{F}^{2}$ by full matrix least-squares techniques using SHELX programs (G.M. Sheldrick, 2016). All non-H atoms were refined anisotropically and the $\mathrm{H}$ atoms were included in the calculation without refinement. Multiscan empirical absorption was corrected using CrysAlisPro program (CrysAlisPro, Agilent Technologies, V1.171.37.35g, 2014). A summary of the crystallographic data and the structure refinement is given in Tables 5 and 6. CCDC 1971786 to CCDC 1971792 contain the supplementary crystallographic data for this paper. These data can be obtained free of charge from The Cambridge Crystallographic Data Centre via www.ccdc.cam.ac.uk/data request/cif. 
Table 5. Crystallographic data, details of data collection and structure refinement parameters for the neutral donors

\begin{tabular}{|c|c|c|c|}
\hline & (S)-1a & rac-1a & $(S, S)-\mathbf{1 b}$ \\
\hline$M\left[\mathrm{gmol}^{-1}\right]$ & 394.57 & 394.57 & 408.60 \\
\hline crystal system & Monoclinic & Monoclinic & Monoclinic \\
\hline space group & $P 2_{1}$ & $P 2_{1}$ & $P 2_{1}$ \\
\hline$c[\AA]$ & $9.6921(11)$ & $9.6707(11)$ & $11.0046(15)$ \\
\hline$B\left[^{\circ}\right]$ & $90.056(9)$ & $90.040(8)$ & $106.850(5)$ \\
\hline$V\left[\AA^{3}\right]$ & $774.26(13)$ & $774.25(11)$ & $846.56(16)$ \\
\hline$Z$ & 2 & 2 & 2 \\
\hline$\rho_{\text {calcd }}\left[\mathrm{gcm}^{-3}\right]$ & 1.692 & 1.692 & 1.603 \\
\hline $\mathrm{R} 1 / w \mathrm{R} 2$ (all data) & $\mathrm{R} 1=0.0746, \mathrm{wR} 2=0.1413$ & $R 1=0.0651, w R 2=0.1722$ & $\mathrm{R}_{1}=0.0852, w \mathrm{R}_{2}=0.1162$ \\
\hline Absolute structure parameter & $0.00(7)$ & $0.06(11)$ & $0.04(6)$ \\
\hline
\end{tabular}

Table 6. Crystallographic data, details of data collection and structure refinement parameters for the radical cation salts

\begin{tabular}{|c|c|c|c|c|}
\hline & {$[(S, S)-\mathbf{1 b}]_{2} \mathrm{ClO}_{4}$} & {$[(R, R)-\mathbf{1 b}]_{2} \mathrm{ClO}_{4}$} & {$[(S, S)-\mathbf{1 b}]_{2} \mathrm{ReO}_{4}$} & {$[(R, R)-\mathbf{1 b}]_{2} \mathrm{ReO}_{4}$} \\
\hline formula & $\mathrm{C}_{48} \mathrm{H}_{48} \mathrm{Cl}_{2} \mathrm{~N}_{8} \mathrm{O}_{16} \mathrm{~S}_{24}$ & $\mathrm{C}_{48} \mathrm{H}_{48} \mathrm{Cl}_{2} \mathrm{~N}_{8} \mathrm{O}_{16} \mathrm{~S}_{24}$ & $\mathrm{C}_{48} \mathrm{H}_{48} \mathrm{~N}_{8} \mathrm{O}_{16} \mathrm{Re}_{2} \mathrm{~S}_{24}$ & $\mathrm{C}_{48} \mathrm{H}_{48} \mathrm{~N}_{8} \mathrm{O}_{16} \mathrm{Re}_{2} \mathrm{~S}_{24}$ \\
\hline$M\left[\mathrm{gmol}^{-1}\right]$ & 1833.28 & 1833.28 & 2134.78 & 2134.78 \\
\hline$T[\mathrm{~K}]$ & $150.0(1)$ & $150.00(10)$ & $150.00(10)$ & $150.00(10)$ \\
\hline crystal system & Monoclinic & Monoclinic & Monoclinic & Monoclinic \\
\hline space group & $P 2_{1}$ & $P 2_{1}$ & $P 2_{1}$ & $P 2_{1}$ \\
\hline$a[\AA]$ & $17.0529(9)$ & $17.1432(8)$ & $17.2074(6)$ & $17.2047(3)$ \\
\hline$b[\AA]$ & $12.6806(3)$ & $12.6889(3)$ & $12.6806(3)$ & $12.6677(2)$ \\
\hline$c[\AA]$ & $17.1325(9)$ & $17.1636(7)$ & $17.3633(5)$ & $17.3593(3)$ \\
\hline$B\left[^{\circ}\right]$ & $113.142(6)$ & $113.455(5)$ & $113.743(4)$ & $113.712(2)$ \\
\hline$V\left[\AA^{3}\right]$ & $3406.6(3)$ & $3425.1(3)$ & $3468.0(2)$ & $3463.96(10)$ \\
\hline$Z$ & 2 & 2 & 2 & 2 \\
\hline$\rho_{\text {calcd }}\left[\mathrm{gcm}^{-3}\right]$ & 1.787 & 1.778 & 2.044 & 2.047 \\
\hline$\mu\left[\mathrm{mm}^{-1}\right]$ & 8.357 & 8.312 & 14.087 & 14.104 \\
\hline goodness-of-fit on $\mathrm{F}^{2}$ & 1.072 & 1.067 & 1.041 & 1.052 \\
\hline final $\mathrm{R} 1 / w \mathrm{R} 2[\mathrm{I}>$ & $R_{1}=0.0831, w R_{2}=$ & $\mathrm{R}_{1}=0.0763, w \mathrm{R}_{2}=$ & $\mathrm{R}_{1}=0.0458, w \mathrm{R}_{2}=$ & $\mathrm{R}_{1}=0.0482, \mathrm{wR}_{2}=$ \\
\hline $2 \sigma(I)]$ & 0.2315 & 0.2380 & 0.1180 & 0.1252 \\
\hline R1/wR2 (all data) & $\begin{array}{l}R_{1}=0.1061, w R_{2}= \\
0.2691\end{array}$ & $\begin{array}{l}\mathrm{R}_{1}=0.0952, w \mathrm{R}_{2}= \\
0.2566\end{array}$ & $\begin{array}{l}R_{1}=0.0551, w R_{2}= \\
0.1258\end{array}$ & $\begin{array}{l}R_{1}=0.0557, w R_{2}= \\
0.1328\end{array}$ \\
\hline $\begin{array}{l}\text { Absolute structure } \\
\text { parameter }\end{array}$ & $0.00(4)$ & $0.125(16)$ & $0.019(13)$ & $0.033(17)$ \\
\hline
\end{tabular}

\section{Computational details}

The tight-binding band structure calculations were of the extended Hückel type. ${ }^{57} \mathrm{~A}$ modified WolfsbergHelmholtz formula was used to calculate the non-diagonal $\mathrm{H}_{\mu \nu}$ values. ${ }^{58}$ All valence electrons were taken into account in the calculations and the basis set consisted of Slater-type orbitals of double- $\zeta$ quality for $\mathrm{C}, \mathrm{N}$ and $\mathrm{O}$ $2 s$ and $2 p, S 3 s$ and $3 p$ and of single- $\zeta$ quality for $\mathrm{H}$. The ionization potentials, contraction coefficients and exponents were taken from previous work. ${ }^{59,34}$

The first-principles spin-polarized calculations were carried out using a numeric atomic orbitals density functional theory (DFT) approach ${ }^{60,61}$ developed for efficient calculations in large systems and implemented in SIESTA code. ${ }^{62,63,64}$ We used the generalized gradient approximation (GGA) to DFT and, in particular, the 
functional of Perdew, Burke, and Ernzerhof. ${ }^{65}$ Only the valence electrons are considered in the calculation, with the core being replaced by norm-conserving scalar relativistic pseudopotentials ${ }^{66}$ factorized in the KleinmanBylander form. ${ }^{67}$ We have used a split-valence double- $\zeta$ basis set including polarization orbitals with an energy shift of 10 meV for all atoms. ${ }^{68}$ The energy cutoff of the real space integration mesh was 350 Ry. The Brillouin zone was sampled using a grid of $(3 \times 5 \times 5) k$-points. ${ }^{69}$ The crystal structure at room temperature was used for the calculations.

\section{Conductivity measurements}

Resistivity measurements were carried out on needle-shaped single crystals of $[(S, S)-\mathbf{1 b}]_{2} \mathrm{ClO}_{4}$ and $[(R, R)$ $\mathbf{1 b}]_{2} \mathrm{ReO}_{4}$ in the temperature range 300-150K. To perform the electrical contacts, gold wires were attached directly to the crystals with silver paint. Two-probe DC measurements were performed applying a constant voltage in the range 2-10V and measuring the current using a Keithley 6487 Picoammeter/Voltage Source. Low temperature was provided by a home-made cryostat equipped with a $4 \mathrm{~K}$ pulse-tube.

\section{ASSOCIATED CONTENT}

\section{Supporting Information}

The Supporting Information is available free of charge on the ACS Publications website at DOI: ..... Additional figures and tables as mentioned in the text (PDF).

\section{Accession Codes}

CCDC 1971786 ((S)-1a), CCDC 1971787 (rac-1a), CCDC 1971788 ((S,S)-1b), CCDC 1971789 ([(S,S)-1b] $\left.{ }_{2} \mathrm{ClO}_{4}\right)$, CCDC $1971790\left([(R, R)-\mathbf{1 b}]_{2} \mathrm{ClO}_{4}\right), \quad \operatorname{CCDC} 1971791\left([(S, S)-\mathbf{1 b}]_{2} \mathrm{ReO}_{4}\right), \operatorname{CCDC} 1971792\left([(R, R)-\mathbf{1 b}]_{2} \mathrm{ReO}_{4}\right)$ contain the supplementary crystallographic data for this paper. These data can be obtained free of charge via www.ccdc.cam.ac.uk/data_request/cif, or by emailing data_request@ccdc.cam.ac.uk, or by contacting The Cambridge Crystallographic Data Centre, 12 Union Road, Cambridge CB2 1EZ, UK; fax: +44 1223336033.

\section{AUTHOR INFORMATION}

Corresponding Authors

*E-mail: flavia.pop@univ-angers.fr; narcis.avarvari@univ-angers.fr; tel: (+33)241735084.

\section{ORCID}

Nicolas Vanthuyne: 0000-0003-2598-7940

Flavia Pop: 0000-0003-3524-9781

Père Alemany: 0000-0002-3139-6189

Enric Canadell: 0000-0002-4663-5226

Narcis Avarvari: 0000-0001-9970-4494

\section{Notes}

The authors declare no competing financial interest. 


\section{ACKNOWLEDGMENTS}

This work was supported in France by the National Agency for Research (ANR, Project 15-CE29-0006-01 ChiraMolCo), the CNRS and the University of Angers. . Work in Spain was supported by MICIU (PGC2018-096955B-C44 and PGC2018-093863- B-C22), MINECO through the Severo Ochoa (SEV-2015-0496) and Maria deMaeztu (MDM-2017-0767) Programs and the Generalitat de Catalunya (2017SGR1506 and 2017SGR1289). Ingrid Freuze and Sonia Jerjir (University of Angers) are gratefully acknowledged for the MS characterization.

\section{REFERENCES}

(1) Pop, F.; Avarvari, N. Covalent non-Fused Tetrathiafulvalene-Acceptor Systems. Chem. Commun. 2016, 52, 7906-7927.

(2) Bendikov, M.; Wudl, F.; Perepichka, D. F. Tetrathiafulvalenes, Oligoacenenes, and Their Buckminsterfullerene Derivatives: The Brick and Mortar of Organic Electronics. Chem. Rev. 2004, 104, 4891-4945.

(3) Bergkamp, J. J.; Decurtins, S.; Liu, S.-X. Current Advances in Fused Tetrathiafulvalene Donor-Acceptor Systems Chem. Soc. Rev. 2015, 44, 863-874.

(4) Yamada, J.-I. TTF Chemistry: Fundamentals and Applications of Tetrathiafulvalene. Springer-Verlag, Berlin and Heidelberg, 2004.

(5) Ishiguro, T.; Yamaji, K.; Saito, G. Organic Superconductors. Heidelberg, Springer-Verlag, 1998.

(6) Canevet, D.; Sallé, M.; Zhang, G.; Zhang, D.; Zhu, D. Tetrathiafulvalene (TTF) Derivatives: Key Building-Blocks for Switchable Processes. Chem. Commun. 2009, 2245-2269.

(7) Lorcy, D.; Bellec, N.; Fourmigué, M.; Avarvari, N. Tetrathiafulvalene-Based Group XV Ligands: Synthesis, Coordination Chemistry and Radical Cation Salts. Coord. Chem. Rev. 2009, 253, 1398-1438.

(8) Fourmigué, M.; Batail, P. Activation of Hydrogen- and Halogen-Bonding Interactions in Tetrathiafulvalene-Based Crystalline Molecular Conductors. Chem. Rev. 2004, 104, 5379-5418.

(9) Mercier, N.; Giffard, M.; Pilet, G.; Allain, M.; Hudhomme, P.; Mabon, G.; Levillain, E.; Gorgues A.; Riou, A. $(\mathrm{TTF})_{2}\left[\mathrm{TTF}\left(\mathrm{CO}_{2} \mathrm{H}\right)_{2}\left(\mathrm{CO}_{2}\right)_{2}\right]$ : a wholly TTF Material Containing TTF Radical Cations and TTF Derived Anions. Chem. Commun. 2001, 2722-2723.

(10) Kobayashi, Y.; Yoshioka, M.; Saigo, K.; Hashizume, D.; Ogura, T. Hydrogen-Bonding-Assisted Self-Doping in Tetrathiafulvalene (TTF) Conductor. J. Am. Chem. Soc. 2009, 131, 9995-10002.

(11) Zhu, Q.-Y.; Han, Q.-H.; Shao, M.-Y.; Gu, J.; Shi, Z.; Dai, J. Supramolecular and Redox Chemistry of Tetrathiafulvalene Monocarboxylic Acid with Hydrogen-Bonded Pyridine and Bipyridine Molecules. J. Phys. Chem. B 2012, 116, 4239-4247.

(12) Simao, C.; Mas-Torrent, M.; André, V.; Duarte, M. T.; Techert, S.; Veciana, J.; Rovira, C. Solid State Photodimerisation of Tetrathiafulvalene Derivatives Bearing Carboxylate and Carboxylic Acid Substituents. CrystEngComm 2013, 15, 98789884.

(13) Bryce, M. R.; Skabara, P. J.; Moore, A. J.; Batsanov, A. S.; Howard, J. A. K.; Hoy, V. J. Synthesis of New Monofunctionalised Tetrathiafulvalene Derivatives by Reactions of Tetrathiafulvalenyllithium with Aldehydes and Ketones: X-Ray Crystal Structures of TTF-CMe(OH)Fc, TTF-CMe(OMe)Fc and TTF-CH(OMe)TTF (Fc = ferrocenyl). Tetrahedron 1997, 53, 17781-17794.

(14) Liu, S.-X.; Neels, A.; Stoeckli-Evans, H.; Pilkington, M.; Wallis, J. D.; Decurtins, S. Organosulfur Donor with Hydroxy Groups and its Conducting Salt: Crystal Structures and Physical Properties. Polyhedron 2004, 23, 1185-1189.

(15) Blanchard, P.; Boubekeur, K.; Sallé, M.; Duguay, G.; Jubault, M.; Gorgues, A.; Martin, J. D.; Canadell, E.; Auban-Senzier, P.; Jérome, D.; Batail, P. A Construction Principle of the $\kappa$-Phase Based on the Efficient $(\mathrm{O}-\mathrm{H})_{\text {donor }} \cdots \mathrm{O}_{\text {anion }}$ Structural Functionality: The Examples of $\kappa-\left(\mathrm{EDT}-\mathrm{TTF}\left(\mathrm{CH}_{2} \mathrm{OH}\right)\right)_{2} \mathrm{X}\left(\mathrm{X}=\mathrm{ClO}_{4}{ }^{-}\right.$and $\left.\mathrm{ReO}_{4}{ }^{-}\right)$. Adv. Mater. 1992, 4, 579-581.

(16) Dolbecq, A.; Fourmigué, M.; Batail, P. ; Coulon, C. From Racemic Mixtures of Chiral $\pi$-Donor Molecules to Mixed Stacks of H-Bonded Centrosymmetrical Dimers of Cation and Anion Radicals with Singlet-Triplet Excitations: The Example of $\left[( \pm)_{3} \mathrm{MTF}_{3} \mathrm{C}^{*} \mathrm{H}(\mathrm{MeOH})^{*+}\right]_{2}\left[\mathrm{TCNQ}^{*}\right]_{2}$ (TTF = Tetrathiafulvalene; TCNQ = Tetracyanoquinodimethane). Chem. Mater. 1994, 6, 1413-1418.

(17) Awheda, I.; Krivickas, S. J.; Yang, S.; Martin, L.; Guziak, M. A.; Brooks, A. C.; Pelletier, F.; Le Kerneau, M.; Day, P.; Horton, P. N.; Akutsu, H.; Wallis, J. D. Synthesis of New Chiral Organosulfur Donors with Hydrogen Bonding Functionality and their First Charge Transfer Salts. Tetrahedron 2013, 69, 8738-8750.

(18) Murata, T.; Maki, S.; Ohmoto, M.; Miyazaki, E.; Umemoto, Y.; Nakasuji, K.; Morita, Y. Redox-Active Tubular Frameworks with TTF: Self-Assemblies by Complementary Hydrogen-Bonds and $\pi$-Stacks of TTF-Phenyluracil. CrystEngComm 2011, $13,6880-6884$.

(19) Neilands, O.; Belyakov, S.; Tilika, V.; Edžina, A. Synthesis and X-Ray Crystal Structure of a Novel Tetrathiafulvalene Dimethyl[2,4-dioxo $(1 \mathrm{H}, 3 \mathrm{H})$ pyrimido]tetrathiafulvalene, Able to Form Intermolecular Hydrogen Bonds of Nucleic Acid Base-Pair Type. J. Chem. Soc., Chem. Commun. 1995, 325-326.

(20) Morita, Y.; Murata, T.; Nakasuji, K. Cooperation of Hydrogen-Bond and Charge-Transfer Interactions in Molecular Complexes in the Solid State. Bull. Chem. Soc. Jpn. 2013, 86, 183-197. 
(21) Murata, T.; Nakasuji, K.; Morita, Y. Tetrathiafulvalene-Type Electron Donors Bearing Biimidazole Moieties: Multifunctional Units with Hydrogen Bonding Abilities. Eur. J. Org. Chem. 2012, 4123-4129.

(22) Murata, T.; Morita, Y.; Fukui, K.; Sato, K.; Shiomi, D.; Takui, T.; Maesato, M.; Yamochi, H.; Saito, G.; Nakasuji, K. A Purely Organic Molecular Metal Based on a Hydrogen-Bonded Charge-Transfer Complex: Crystal Structure and Electronic Properties of TTF-Imidazole-p-Chloranil. Angew. Chem. Int. Ed. 2004, 43, 6343-6346.

(23) Ueda, A.; Mori, H. A Phenol-Fused Tetrathiafulvalene: Modulation of Hydrogen-Bond Patterns and Electrical Conductivity in the Charge-Transfer Salt. Mater. Chem. Front. 2018, 2, 566-572.

(24) Kamo, H.; Ueda, A.; Isono, T.; Takahashi, K.; Mori, H. Synthesis and Properties of Catechol-Fused Tetrathiafulvalene Derivatives and their Hydrogen-Bonded Conductive Charge-Transfer Salts. Tetrahedron Lett. 2012, 53, 4385-4388.

(25) Isono, T.; Kamo, H.; Ueda, A.; Takahashi, K.; Nakao, A.; Kumai, R.; Nakao, H.; Kobayashi, K.; Murakami, Y.; Mori, H. Hydrogen Bond-Promoted Metallic State in a Purely Organic Single-Component Conductor under Pressure. Nat. Commun. 2013, 4, 1344.

(26) Yoshida, J.; Ueda, A.; Nakao, A.; Kumai, R.; Nakao, H.; Murakami, Y.; Mori, H. Solid-Solid Phase Interconversion in an Organic Conductor Crystal: Hydrogen-Bond-Mediated Dynamic Changes in $\pi$-Stacked Molecular Arrangement and Physical Properties. Chem. Commun. 2014, 50, 15557-15560.

(27) Ueda, A.; Hatakeyama, A.; Enomoto, M.; Kumai, R.; Murakami, Y.; Mori, H. Modulation of a Molecular $\pi$-Electron System in a Purely Organic Conductor that Shows Hydrogen-Bond-Dynamics-based Switching of Conductivity and Magnetism. Chem. Eur. J. 2015, 21, 15020-15028.

(28) Heuzé, K.; Fourmigué, M.; Batail, P. The Crystal Chemistry of Amide-Functionalized Ethylenedithiotetrathiafulvalenes: EDT-TTF-CONRR' (R, R' = H, Me). J. Mater. Chem. 1999, 9, 2373-2379.

(29) Heuzé, K.; Fourmigué, M.; Batail, P.; Canadell, E.; Auban-Senzier, P. Directing the Structures and Collective Electronic Properties of Organic Conductors: The Interplay of $\pi$-Overlap Interactions and Hydrogen Bonds. Chem. Eur. J. 1999, 5, 2971-2976.

(30) Heuzé, K.; Mézière, C.; Fourmigué, M.; Batail, P.; Coulon, C.; Canadell, E.; Auban-Senzier, P.; Jérome, D. An Efficient, Redox-Enhanced Pair of Hydrogen-Bond Tweezers for Chloride Anion Recognition, a Key Synthon in the Construction of a Novel Type of Organic Metal based on the Secondary Amide-Functionalized Ethylenedithiotetrathiafulvalene, $\beta^{\prime \prime}$ (EDT-TTF-CONHMe) $)_{2}\left[\mathrm{Cl} \cdot \mathrm{H}_{2} \mathrm{O}\right]$. Chem. Mater. 2000, 12, 1898-1904.

(31) Devic, T.; Avarvari, N.; Batail, P. A Series of Redox Active, Tetrathiafulvalene-Based Amido-Pyridines and Bipyridines Ligands: Syntheses, Crystal Structures, Radical Cation Salt and Group 10 Transition Metal Complexes. Chem. Eur. J. 2004, 10, 3697-3707.

(32) Devic, T.; Batail, P.; Avarvari, N. [2+2]Photocyclization in a Single-Crystal-to-Single-Crystal Transformation of a TTFAmido-Pyridine. Chem. Commun. 2004, 1538-1539.

(33) Baudron, S. A.; Avarvari, N.; Batail, P.; Coulon, C.; Clérac, R.; Canadell, E.; Auban-Senzier, P. Singular Crystalline $\beta^{\prime}$ Layered Topologies Directed by Ribbons of Self-Complementary Amide $\bullet \bullet A$ Amide Ring Motifs in [EDT-TTF- $\left.\left(\mathrm{CONH}_{2}\right)_{2}\right]_{2} \mathrm{X}$ $\left(\mathrm{X}=\mathrm{HSO}_{4}^{-}, \mathrm{ClO}_{4}^{-}, \mathrm{ReO}_{4}^{-}, \mathrm{AsF}_{6}{ }^{-}\right)$: Coupled Activation of Ribbon Curvature, Electron Interactions, and Magnetic Susceptibility. J. Am. Chem. Soc. 2003, 125, 11583-11590.

(34) Baudron, S. A.; Avarvari, N.; Canadell, E.; Auban-Senzier, P.; Batail, P. Structural Isomerism in Crystals of Redox-Active Secondary ortho-Diamides: The Role of Competing Intra- and Intermolecular Hydrogen Bonds in Directing Crystalline Topologies. Chem. Eur. J. 2004, 10, 4498-4511.

(35) Shi, Z.; Lu, Z.-J.; Zhu, Q.-Y.; Huo, L.-B.; Han, Q.-H.; Bian, G.-Q.; Dai, J. Diamino-Diamido Tetrathiafulvalene for the Sensing of Anions and Cations: A View in Electrochemistry and Structure. J. Phys. Chem. B 2011, 115, 3020-3026.

(36) Kaneko, R.; Wu, G.; Sugawa, K.; Otsuki, J. Intermolecular Electronic Communication in Tetrathiafulvalene Derivatives with Hydrogen-Bonding Amide Units. Asian J. Org. Chem. 2018, 7, 897-901.

(37) Réthoré, C.; Fourmigué, M.; Avarvari, N. Chiral Tetrathiafulvalene-Hydroxyamides and -Oxazolines: Hydrogen Bonding, Chirality, and a Radical Cation Salt. Tetrahedron 2005, 61, 10935-10942.

(38) Tatewaki, Y.; Hatanaka, T.; Tsunashima, R.; Nakamura, T.; Kimura, M.; Shirai, H. Conductive Nanoscopic Fibrous Assemblies Containing Helical Tetrathiafulvalene Stacks. Chem. Asian J. 2009, 4, 1474-1479.

(39) Saad, A.; Jeannin, O.; Fourmigué, M. Helical Organization of Chiral Binaphthyl Tetrathiafulvalene Primary Amides through Hydrogen Bonding Interactions. CrystEngComm 2010, 12, 3866-3874.

(40) Danila, I.; Riobé, F.; Piron, F.; Puigmartí-Luis, J.; Wallis, J. D.; Linares, M.; Ågren, H.; Beljonne, D.; Amabilino, D. B.; Avarvari, N. Hierarchical Chiral Expression from the Nano- to Mesoscale in Synthetic Supramolecular Helical Fibers of a Nonamphiphilic C3-Symmetrical $\pi$-Functional Molecule. J. Am. Chem. Soc. 2011, 133, 8344-8353.

(41) Danila, I.; Pop, F.; Escudero, C.; Feldborg, L. N.; Puigmartí-Luis, J.; Riobé, F.; Avarvari, N.; Amabilino, D. B. Twists and Turns in the Hierarchical Self-Assembly Pathways of a non-Amphiphilic Chiral Supramolecular Material. Chem. Commun. 2012, 48, 4552-4554.

(42) Pop, F.; Melan, C.; Danila, I.; Linares, M.; Beljonne, D.; Amabilino, D. B.; N. Avarvari, N. Hierarchical Self-Assembly of Supramolecular Helical Fibres from Amphiphilic $C_{3}$-Symmetrical Functional Tris(tetrathiafulvalenes). Chem. Eur. J. 2014, 20, 17443-17453.

(43) Avarvari, N.; Wallis, J. D. Strategies Towards Chiral Molecular Conductors. J. Mater. Chem. 2009, 19, 4061-4076.

(44) Pop, F.; Avarvari, N. Chiral Metal-Dithiolene Complexes. Coord. Chem. Rev. 2017, 346, $20-31$.

(45) Pop, F.; Zigon, N.; Avarvari, N. Main-Group-Based Electro- and Photoactive Chiral Materials. Chem. Rev. 2019, 119, 8435-8478. 
(46) Réthoré, C.; Avarvari, N.; Canadell, E.; Auban-Senzier, P.; Fourmigué, M. Chiral Molecular Metals: Syntheses, Structures and Properties of the $\mathrm{AsF}_{6}{ }^{-}$Salts of Racemic (+/-), $(R)$ - and $(S)$-Tetrathiafulvalene-Oxazoline Derivatives. J. Am. Chem. Soc. 2005, 127, 5748-5749.

(47) Madalan, A. M.; Réthoré, C.; Fourmigué, M.; Canadell, E.; Lopes, E. B.; Almeida, M.; Auban-Senzier, P.; Avarvari, N. Order versus Disorder in Chiral Tetrathiafulvalene-Oxazolines Radical Cation Salts: Structural, Theoretical Investigations and Physical Properties. Chem. Eur. J. 2010, 16, 528-537.

(48) Pop, F.; Auban-Senzier, P.; Frąckowiak, A.; Ptaszyński, K.; Olejniczak, I.; Wallis, J. D.; Canadell, E.; Avarvari, N. Chirality Driven Metallic versus Semiconducting Behavior in a Complete Series of Radical Cation Salts Based on DimethylEthylenedithio-Tetrathiafulvalene (DM-EDT-TTF). J. Am. Chem. Soc. 2013, 135, 17176-17186.

(49) Pop, F.; Auban-Senzier, P.; Canadell, E.; Avarvari, N. Anion Size Control of the Packing in the Metallic versus Semiconducting Chiral Radical Cation Salts (DM-EDT-TTF) ${ }_{2} \mathrm{XF}_{6}(\mathrm{X}=\mathrm{P}, \mathrm{As}, \mathrm{Sb})$. Chem. Commun. 2016, 52, 12438-12441.

(50) Rikken, G. L. J. A.; Fölling, J.; Wyder, P. Electrical Magnetochiral Anisotropy. Phys. Rev. Lett. 2001, 87, 236602-1-4.

(51) Krstić, V.; Roth, S.; Burghard, M.; Kern, K.; Rikken, G. L. J. A. Magneto-Chiral Anisotropy in Charge Transport Through Single-Walled Carbon Nanotubes. J. Chem. Phys. 2002, 117, 11315-11319.

(52) Pop, F.; Auban-Senzier, P.; Canadell, E.; Rikken, G. L. J. A.; Avarvari, N. Electrical Magneto-Chiral Anisotropy in a Bulk Chiral Molecular Conductor. Nat. Commun. 2014, 5, 3757.

(53) Mroweh, N.; Auban-Senzier, P.; Vanthuyne, N.; Canadell, E.; Avarvari, N. Chiral EDT-TTF Precursors with one Stereogenic Centre: Substituent Size Modulation of the Conducting Properties in the (R-EDT-TTF) ${ }_{2} \mathrm{PF}_{6}(\mathrm{R}=\mathrm{Me}$ or Et) Series. J. Mater. Chem. C 2019, 7, 12664-12673.

(54) Cauchy, T.; Pop, F.; Cuny, J.; Avarvari, N. Conformational Study and Chiroptical Properties of Chiral DimethylEthylenedithio-Tetrathiafulvalene (DM-EDT-TTF). Chimia 2018, 72, 389-393.

(55) Whangbo, M.-H.; Williams, J. M.; Leung, P. C. W.; Beno, M. A.; Emge, T. J.; Wang, H. H. Role of the Intermolecular Interactions in the Two-Dimensional Ambient-Pressure Organic Superconductors $b$ - $\left.(\mathrm{ET})_{2}\right|_{3}$ and $b-\left(\mathrm{ET}_{2}\right)_{2} \mid \mathrm{Br}{ }_{2}$. Inorg. Chem. 1985, 24, 3500-3502.

(56) Sahadevan, S. A.; Monni, N.; Abhervé, A.; Auban-Senzier, P.; Canadell, E.; Mercuri, M. L.; Avarvari, N. Synthesis and Physical Properties of Purely Organic BEDT-TTF-based Conductors Containing Hetero-/Homosubstituted Cl/CN-Anilate Derivatives. Inorg. Chem. 2017, 56, 12564-12571.

(57) Whangbo, M.-H.; Hoffmann, R. The Band Structure of the Tetracyanoplatinate Chain J. Am. Chem. Soc. 1978, 100, 60936098.

(58) Ammeter, J. H.; Bürgi, H.-B.; Thibeault, J.; Hoffmann, R. Counterintuitive Orbital Mixing in Semiempirical and ab Initio Molecular Orbital Calculations. J. Am. Chem. Soc. 1978, 100, 3686-3692.

(59) Pénicaud, A.; Boubekeur, K.; Batail, P.; Canadell, E.; Auban-Senzier, P.; Jérome, D. Hydrogen-Bond Tuning of Macroscopic Transport Properties from the Neutral Molecular Component Site along the Series of Metallic OrganicInorganic Solvates (BEDT-TTF) ${ }_{4} \mathrm{Re}_{6} \mathrm{Se}_{5} \mathrm{C} 1_{9}$. [guest], [guest = DMF, THF, dioxane]. J. Am. Chem. Soc. 1993, 115, 4101-4112.

(60) Hohenberg, P.; Kohn, W. Inhomogeneous Electron Gas. Phys. Rev., 1965, 136, B864-B871.

(61) Kohn, W.; Sham L. J. Self-Consistent Equations Including Exchange and Correlation Effects. Phys. Rev., 1965, 140, A1133A1138.

(62) Soler J. M.; Artacho E.; Gale J. D.; García A.; Junquera J.; Ordejón P.; Sánchez-Portal, D. J. The SIESTA method for ab initio order-N materials simulation. J. Phys.: Condens. Matter. 2002, 14, 2745-2779.

(63) Artacho, E.; Anglada, E.; Diéguez, O.; Gale, J. D.; García, A.; Junquera, J.; Martin, R. M.; Ordejón, P.; Pruneda, J. M.; Sánchez-Portal, D.; Soler J. M. J. The SIESTA method: developments and applicability. Phys.: Condens. Matter. 2008, 20, 064208.

(64) For more information on the SIESTA code visit: http://departments.icmab.es/leem/siesta/

(65) Perdew, J. P.; Burke, K.; Ernzerhof, M. Generalized Gradient Approximation Made Simple. Phys. Rev. Lett. 1966, 77, 38653868.

(66) Troullier, N.; Martins J. L. Efficient Pseudopotentials for plane-wave calculations. Phys. Rev. B 1991, 43, $1993-2006$

(67) Kleinman, L.; Bylander, D. M. Efficacious Form for Model Pseudopotentials. Phys. Rev. Lett. 1982, 48, $1425-1428$.

(68) Artacho, E.; Sánchez-Portal, D.; Ordejón, P.; García, A.; Soler, J. M. Linear Scaling ab-initio Calculations for Large and Complex Systems. Phys. Stat. Sol. (b) 1999, 215, 809-817.

(69) Monkhorst, H. J.; Pack J. D. Special points for Brillouin zone integrations. Phys. Rev. B 1976, 13, 5188-5192. 